\title{
Shooting Stars? Uncertainty in Hiring Entrepreneurs
}

\begin{abstract}
Research Summary: This article advances a theory to explain why a spell of entrepreneurship affects the future wages of entrepreneurs returning to the wage sector. We propose that entrepreneurship holds a low rather than a negative information value, increasing the uncertainty around a job applicant's future productivity. Employers respond to this uncertainty by discounting the offered wage. The theory predicts that uncertainty in hiring - and thus the wage penalty is more pronounced for entrepreneurs (i) who were in the upper tail of the wage distribution before the entrepreneurial spell, (ii) who exited entrepreneurship quickly, and (iii) who are hired by small employers. We test and find empirical support for these predictions using a novel dataset of matched entrepreneurs and employees from Belgium.

Managerial Summary: We investigate the effect of past entrepreneurial experience on the future wages of entrepreneurs who go back to paid employment. We propose that former entrepreneurs receive a pay cut because employers consider them as risky hires. In line with our theory, we find that former entrepreneurs are penalized the most (i) if they were highly paid employees before becoming founders, (ii) if they were entrepreneurs only for a few years, (iii) and if they are hired by small employers. Our findings caution star employees from experimenting with an entrepreneurial career, as failing fast is costly. Moreover, we suggest that firms value probationary contracts to lower the risk of hiring entrepreneurs while learning about their skills.
\end{abstract}

Keywords: Entrepreneurship, returns, prior wage, uncertainty, stigma of failure. 


\section{Introduction}

A fundamental question at the heart of entrepreneurship is why individuals become entrepreneurs. A substantial volume of research recognizes that this choice is the outcome of a trade-off between opportunity costs and the expected returns from entrepreneurship, which include both pecuniary and non-pecuniary benefits (Fairlie, 2002; Hamilton, 2000). More recently, scholars and policy makers have viewed entrepreneurship also as a way to experiment with ideas and career options (e.g., Polkovnichenko, 2003; Kerr et al., 2014; Manso, 2016). The implicit assumption is that in case of failure or mismatch with a person's own abilities and preferences, it is always possible for the entrepreneur to easily quit and find a job back in the wage sector. Indeed, moves between paid employment and entrepreneurship are rather common, and most entrepreneurs return to the wage sector within a few years (e.g., Kaiser and Malchow-Møller, 2011; Dillon and Stanton, 2017). However, for individuals contemplating founding a company to experiment with ideas, knowing whether their future salary will be jeopardized upon returning to the wage sector is valuable.

Recent research has begun to document the consequences of such entrepreneurial attempts. Apart from a few exceptions (Hyytinen and Rouvinen, 2008; Luzzi and Sasson, 2016; Manso, 2016), existing evidence indicates that entrepreneurs, on average, receive a pay cut when rejoining the labor market immediately after a spell of entrepreneurship (see e.g., Bruce and Schuetze, 2004; Baptista et al., 2012; Failla et al., 2017; Kaiser and Malchow-Møller, 2011). This evidence suggests that labor market frictions could negatively affect the value of experimenting with entrepreneurship (Aksaray and Thompson, 2017; Gottlieb et al., 2016).

However, little is known about the factors driving this adverse treatment. A few scholars suggest that employers discount entrepreneurs because their experience may signal skills or preferences that do not fit with the wage employment context. Furthermore, exiting entrepreneurship may signal firm failure and, in turn, poor individual qualities, given the strong expected association between founder quality and start-up performance (Bruce and Schuetze, 2004; Kaiser and Malchow-Møller, 2011; Koellinger et al., 2015). Overall, the underlying assumption is that entrepreneurial experience holds a signaling value and that this value is negative. Yet, empirical support in favor of these mechanisms 
remains limited.

This paper advances a theory to explain why entrepreneurs are penalized. In developing this theory, we were motivated by recent intriguing insights from labor economics on the role of uncertainty in hiring (Kuhnen and Oyer, 2016). In contrast to previous work, we posit that a (short) spell of entrepreneurship holds a low rather than a high signaling value. The noisiness of the signal increases the uncertainty about an individual's future productivity. Employers respond to this uncertainty in recruitment by offering lower wages to entrepreneurs relative to equivalent employees without entrepreneurial experience. To offer empirical support for this uncertainty-based mechanism, we consider how the degree and importance of uncertainty in the hiring process affects the size of the wage penalty. We predict that the penalty is stronger for entrepreneurs (i) with previous high-ability signals, (ii) who exited quickly, and (iii) who are hired by firms that bear higher firing and replacement costs.

We test our claims by using a newly developed ad hoc longitudinal linked employer-employee dataset from the Belgian Datawarehouse Labor Market and Social Protection, covering all quarters between 2000 and 2015. We construct a matched sample of employees who transition into entrepreneurship and workers who never leave paid employment between the first quarter of 2004 and the last quarter of 2015. The matched group of workers who remain in wage employment serves as a counterfactual example of what would have happened to the entrepreneurs had they not become selfemployed. From this control sample, we select the matched pairs in which the entrepreneurs move from a full-time job to entrepreneurship and back, and compare the wages between the two groups immediately before and after the entrepreneurship spell.

We find strong support for our predictions. The wage penalty is more severe for entrepreneurs who come from the upper end of the wage distribution in the quarter before entering entrepreneurship - here referred to as stars - whereas there is no penalty for those coming from the lower tail. Stars earn around 16 percent less after a spell of entrepreneurship than their matched pairs who remained in wage employment. We also find that the penalty diminishes as uncertainty resolves or when it is inherently absent. Correspondingly, only entrepreneurs who return to the wage sector rel- 
atively quickly - within five years from firm foundation - and who do not return to their previous employer appear to be penalized. Finally, we find that stars' penalty is smaller for entrepreneurs who move to a large employer, presumably because uncertainty is more damaging when the cost of firing and replacing unsuccessful hires is high, as is the case for small firms (Kuhnen and Oyer, 2016; Tate and Yang, 2015).

Our results are robust to several robustness checks, in particular, to different counterfactual groups (stayers, movers, and not yet entrepreneurs) and to relaxations of various sample restrictions. In the supplementary section, we also explore a number of possible alternative explanations based on the extant literature, such as human capital depreciation, expected job mismatches, taste-based discrimination, stigma of failure, sorting on non-pecuniary preferences, and labor market frictions. We discuss how these mechanisms yield predictions that are inconsistent with the empirical evidence presented in this paper. Among a number of potential contributing factors, uncertainty appears to be the sole mechanism that is consistent with all the empirical patterns observed in our data.

This study contributes to our understanding of the returns from entrepreneurship. First, we offer a novel explanation for why entrepreneurs returning to the wage sector are adversely treated. Specifically, we develop and test a theory for which a spell in entrepreneurship increases employers' uncertainty about a job applicant's future productivity. Second, we argue and show that entrepreneurs who were star employees are penalized, whereas those who come from the bottom of the ability distribution are not. With this finding, we extend prior work, which implicitly assumes that the returns from entrepreneurship are independent of one's previous career (e.g., Kaiser and Malchow-Møller, 2011). Moreover, we contribute to research on stars and entrepreneurship (Astebro et al., 2011). While prior work proposes entrepreneurship as an attractive career option for stars (e.g., Groysberg et al., 2007), the stronger penalty we find in case of short spells cautions stars against experimenting with entrepreneurship. Third, the finding that large firms penalize star entrepreneurs less seems at odds with theories about the sorting of entrepreneurial types into small firms based on preferences and skills (Elfenbein et al., 2010), and highlights the importance of accounting for heterogeneity in the demand side when looking at exit from entrepreneurship. Large firms may be better equipped 
in dealing with risky hires. Fourth, our findings suggest that the value of experimenting with new ideas (Manso, 2016) is not equally distributed among entrepreneurs, but it is influenced by their prior status in the labor market and by future employer attributes, similar to how certain employees learn about their fit for a new job by engaging in risky experiments in their current job (Chatterji et al., 2016).

Our evidence supporting the existence of uncertainty in hiring entrepreneurs suggests a reconsideration of the policy focus on reducing the stigma attached to failed entrepreneurs (e.g., Singh et al., 2015) toward measures that mitigate employers' costs of handling uncertainty. Furthermore, it is commonly believed in practice-oriented entrepreneurship communities that a quick exit is desirable if the initial outcomes are negative. Our results suggest that this view is a partial consideration at best and should be called into question. This paper also has implications for managers engaged in the war for talent. Hiring entrepreneurs who were former stars can be seen as a strategic investment decision under uncertainty. From a real options perspective, their lower hiring cost compared to poaching stars from other established firms might be attractive because of their high upside potential, despite the risk of bringing in bad hires. Ultimately, this study cautions against investigating the effect of an entrepreneurial spell on future wages without taking into account previous signals of ability, as employers do not consider the signal of an entrepreneurial experience in isolation but in combination with the signals emerging from the past paid employment experience (Falk and Zimmermann, 2017).

\section{Conceptual Framework}

Labor economists have long recognized that a fundamental problem in hiring is one of matching in the presence of information asymmetries (cf. Oyer and Schaefer, 2011, for an overview). Limited information about the true qualities and effort levels of workers implies that employers must make hiring decisions about a worker's future productivity under uncertainty (Spence, 1973). As employers are unable to discover the true ability of each worker prior to employment, they rely on information gathered from signals that have proven to be effective in predicting workers' productivity. Within the classic Spence (1973) signaling framework, we advance an explanation for the effect of an en- 
trepreneurial spell on the re-entry wage, which focuses on two signals: group identification (Borjas and Goldberg, 1978) and previous salary (e.g., Barach and Horton, 2017; Hall and Krueger, 2012). Signal noise, entrepreneurship, and wage penalty

Signal noise and entrepreneurship

Consider two comparable groups of potential job applicants. The first group consists of individuals who re-enter the wage sector immediately following a spell of entrepreneurship, i.e., the entrepreneurs, whereas the second group consists of workers without entrepreneurial experience, i.e., the employees. Employers observe a signal of group affiliation - entrepreneurs or employees - as well as signals about individual ability - including the previous wage - by considering the candidates' résumés via job interviews or secondary sources (Barach and Horton, 2017). In our empirical setting, all entrepreneurs have wage employment experience, so we can observe their salary just before the entrepreneurial spell.

This paper postulates that employers are more uncertain about the productivity of entrepreneurs than that of employees. In other words, an intermittent spell of entrepreneurship is less informative about the expected productivity in future wage work than a consecutive career trajectory in paid employment. We develop this intuition by drawing on theories of signal substitution in hiring decisions (Autor and Scarborough, 2008; Agan and Starr, 2018; Barach and Horton, 2017; Bertrand and Mullainathan, 2004). This literature demonstrates that in the absence of one or more pieces of information, employers put more weight on other correlated signals in their screening process.

A substantial volume of labor economics literature shows that employers rely extensively on available information about past employment to assess job candidates' fit (e.g., Altonji and Pierret, 2001; Greenwald, 1986; Pallais, 2014; Schönberg, 2007; Waldman, 1984). Among the available information, the previous wage is considered as a strong signal of future productivity, especially if the prior job is similar to the one offered (e.g., Barach and Horton, 2017). Retrieving this information is a common human resources (HR) practice. For example, Hall and Krueger (2012) show that 47 percent of workers reported that their employers had learned about their pay in their earlier jobs before making the offer. Another prominent signal in this literature is past promotions (Waldman, 1984). As 
the actual productivity of an employee is typically unobservable to the prospective employer, a promotion reveals to outside firms a positive signal about worker ability (Gibbons and Katz, 1991; DeVaro and Waldman, 2012; Moallemi et al., 2017). Finally, firms can also directly discern the ability of a new hire by contacting the listed references from past employers (Ioannides and Loury, 2004). In fact, a recent study finds that including a reference letter from a previous boss increases call-backs by more than 60 percent (Abel et al., 2017).

These conventional signals of ability are clearly less available to employers when they evaluate entrepreneurial experience. Therefore, we suggest that when hiring entrepreneurs, employers use substitute signals related to start-up performance, and that these signals are less accurate in predicting future productivity in the wage sector than the signals associated with regular employment experience.

More often than not, the entrepreneur will act as his/her own most suitable reference, as the employer and the employee are collapsed into the single entity of the founder (Lazear, 1981). Therefore, the retrieved information is likely to be biased. While firms can infer the previous wage from secondary independent sources, information about the earnings of an entrepreneur are typically selfreported. Moreover, compared with wages, entrepreneurial earnings are less likely to be correlated with productivity. The entrepreneur's decision on how much earnings to withdraw for himself/herself or whether to re-invest in the company is complex and follows a different logic compared with wage determination in established firms (e.g., Wasserman, 2012). Another piece of information that is likely to be biased is the reason for returning to the wage sector because founders tend to underreport failure or blame the external environment for it (Eggers and Song, 2015). Finally, unlike being assigned to high-level, high-quality jobs in established firms (DeVaro and Waldman, 2012; Waldman, 1984), taking on the founder role does not serve as a credible signal of ability, as individuals may become entrepreneurs for reasons other than economic rewards (Hamilton, 2000).

Signals of ability derived from an entrepreneurial experience may not only be noisier compared with those in the wage sector but also costlier to obtain. While the hiring firms may increase the accuracy of the signal by engaging in a costly search (Barron et al., 1985) to collect detailed infor- 
mation about the start-up and the team, they are often unwilling to do so. For example, Cahn et al. (2017) find that banks that can easily reconstruct information about start-up failure based on public bankruptcy files typically do not do so. Furthermore, directly observing the financial performance of an entrepreneurial venture is difficult for employers. While the yearly financial balance sheets are publicly available, only incorporated ventures (a minority of the start-up population) are required to publish them, often in a reduced form, and typically several months after the closure of the accounting year. Absent data on performance, employers may look at signals correlated with performance, such as the attraction of external financing (Chatterji, 2009), firm size (Elfenbein et al., 2010), and whether the firm is incorporated (Levine and Rubinstein, 2016). Yet, the presence of confounding factors, such as personal social networks, may reduce their signaling value.

Even if firms obtained credible information on start-up performance, evaluating the contribution of the entrepreneur to the performance of his/her venture remains difficult for employers. This is especially the case if the venture is co-founded or has early employees. Moreover, there may be exogenous (industry or macroeconomic) shocks that affect firm performance (e.g., Cahn et al., 2017) and that are therefore independent of founder ability. Lastly, many start-ups fail because of the poor quality of the identified business opportunity (Ries, 2011), which may be largely unrelated to the expected productivity of the founder in the wage sector.

In conclusion, fewer and less-accurate signals characterize the hiring of entrepreneurs. Therefore, we conjecture that ceteris paribus, a spell of entrepreneurship increases the uncertainty that employers face when assessing a new hire's future productivity.

\section{Signal noise and wage penalty}

Uncertainty about an entrepreneur's future productivity may have detrimental effects on his/her competitiveness in the labor market. Labor economics research has documented the role of uncertainty in corporate hiring, finding that employers tend to be averse to such hires (Hendricks et al., 2001) and that uncertainty around a candidate's expected productivity reduces the odds of being hired (Kuhnen and Oyer, 2016). We propose an additional implication of uncertainty: conditional on hiring, uncertainty discounts the offered wage. Therefore, entrepreneurs - the riskier hires - receive a wage 
penalty upon re-entering the labor market compared with observationally similar employees. This prediction is consistent with ample empirical evidence (e.g., Baptista et al., 2012; Failla et al., 2017; Kaiser and Malchow-Møller, 2011).

The main mechanism through which higher uncertainty can induce a pay cut is that employers will demand compensation for uncertainty in case the entrepreneur turns out to be a bad hire. The greater signal noise associated with the entrepreneurial experience increases the risk for the employer that the entrepreneur will not have sufficient ability or commitment to be productive in the assigned job task, resulting in a job mismatch (Jovanovic, 1979). The underlying assumption is that employers are concerned with uncertainty about the expected quality of a job match because it is costly for them to fire and replace an (unproductive) employee (e.g., Pfann, 2006; Serfling, 2016).

This assumption appears to be reasonable in light of the setting we choose for the empirical analysis. We use data from the Belgian labor market, which is characterized by strong employment protection institutions. For example, an employer needs to pay a fired employee a dismissal compensation equivalent to a three-month salary for each five years of tenure. Moreover, to strengthen the soundness of the assumption, we will restrict our sample to full-time permanent jobs. In the instance of a temporary job, the cost of a bad hire is much lower because the employer can simply choose not to continue the employment relation (Kuhnen and Oyer, 2016; Lazear, 1995).

Why, then, do firms hire candidates with an uncertain quality? Uncertainty about entrepreneurs' future productivity can be beneficial because it holds option value (Hendricks et al., 2001; Lazear, 1995). If the candidate turns out to be a good match, then offering a lower wage to former entrepreneurs is an attractive opportunity for firms to hire productive employees at a discounted rate. Entrepreneurs may be willing to accept a lower offer, fearing the possibility of unemployment and its long-term related consequences (Jacobson et al., 1993). Therefore, hiring entrepreneurs can be interpreted through a real option lens (Dixit, 1992) in which uncertainty may limit the amount of investments that are sunk, i.e., the offered wage, while allowing for learning about the upside potential. 


\section{Size of the penalty}

We have claimed that uncertainty about future productivity explains the negative effect of an entrepreneurial experience on the re-entry wage. One way to test support for this claim is to consider whether the factors that predict variation across individuals and firms in the importance of uncertainty also predict variation in the size of the wage penalty. We draw on the extant labor economics literature to identify two sources of heterogeneity in uncertainty: an employee's position in the overall wage distribution and the time spent in entrepreneurship. Moreover, assuming that the importance of uncertainty depends on the cost of a poor match (Kuhnen and Oyer, 2016), we consider employer size as a source of firm-level variation in the costs of replacing a bad hire.

\section{Rank in the wage distribution}

We consider ability as one source of heterogeneity in the entrepreneurs' group with regard to the level of uncertainty faced by employers. Empirically, we will proxy ability by using individual position (rank) in the unconditional wage distribution immediately before the entrepreneurial spell. In line with previous research on entrepreneurship, we will distinguish between entrepreneurs who come from the top of the wage distribution, which we refer to as star employees, and those who come from the bottom (e.g., Astebro et al., 2011; Elfenbein et al., 2010; Groysberg et al., 2007). Using the previous wage as a proxy for ability is consistent with our signaling theoretical framework in which employers rely on previous wage as a signal of ability. We propose that the wage penalty is more severe for entrepreneurs who were high-ability employees.

First, employers have more difficulties in efficiently estimating the productivity of individuals with extreme values of the ability signal (Hendricks et al., 2001) because employers need to base their evaluations of these applicants on a smaller sample size than that for employees with moderate values of the ability signal. This is a particular disadvantage for entrepreneurs with a high signal, as the spell of entrepreneurship weakens the information value of their signal, whereas it is an advantage for entrepreneurs with a low-ability signal. This aversion discount could cause employers to prefer employee candidates with low-ability signal values (Hendricks et al., 2001). 
Second, star entrepreneurs face higher opportunity costs when starting because of the higher wages and employment-related benefits they need to forgo (Amit and Cockburn, 1995; Campbell et al., 2012). These higher opportunity costs raise the threshold of performance required to induce a star employee to remain as an entrepreneur. Despite this, evidence that the entrepreneur returns (quickly) to the wage sector may induce the labor market to discount competing evidence about the founder's ability, including evidence from pre-entrepreneurship earnings.

Third, star employees tend to hold high-level jobs compared with employees who are lower ranked in the wage distribution. Yet, hiring entrepreneurs in high-level jobs may increase the cost of uncertainty because the minimum ability needed to perform effectively and the cost to the firm of ineffective performance are both greater in higher-ranked jobs (Pfann, 2006). At the highest level, an ineffective CEO can be devastating for a firm. It is also generally true that an ineffective engineer or accountant causes more damage than does an ineffective production worker. This remains true even if one can dismiss ineffective workers because turnover costs are significantly higher at higher ranks and discerning that higher-ranked workers are performing ineffectively takes more time.

In short, the empirical prediction we derive from these arguments is that the wage penalty is more severe for entrepreneurs whose previous wage is highly ranked in the overall wage distribution.

\section{Length of the entrepreneurial spell}

Another source of variation in the uncertainty perceived by hiring firms is the length of the entrepreneurial spell. We argue that uncertainty resolves over time in entrepreneurship for two reasons.

First, entrepreneurship-related signals become more accurate with time. Compared with longer spells, quick exits are less informative about the ability of the founder. Whether a quick exit is the result of low-ability individuals selecting out of entrepreneurship or of external economic shocks is difficult to disentangle, as entrepreneurs operating younger and smaller firms are more vulnerable to unanticipated negative shocks (Freeman et al., 1983). A quick exit may also reflect an entrepreneur learning about his/her preferences rather than his/her ability (Manso, 2016), or it may be caused by the poor quality of the business opportunity, which is largely unrelated to ability as an employee.

Second, entrepreneurship-related signals become more available over time. In the previous sec- 
tion, we argued that uncertainty depends not only on the noise of the signal but also on the availability of signals. Accordingly, we argue that over time, firms can make more informed choices without incurring additional search costs. For example, while little information exists about performance in the start-up phase, entrepreneurs who have survived for several years can provide more detailed sales and track records. Moreover, the likelihood that signals associated with firm performance, such as awards, external financing, or endorsements from prominent actors, become available increases over time (e.g., Stuart et al., 1999; Stinchcombe, 1965). If the noise obscuring ability is random, as is usually assumed, the mean of signals converges on the true ability as more signals are observed.

As a consequence, the correlation between the observed outcomes and ability is higher the longer the period over which the outcome is averaged. More importantly, the difference in precision between a high-noise signal (entrepreneurial experience) and a low-noise one (employment experience) becomes smaller the longer the time over which the outcome is averaged. Therefore, we expect the wage penalty to decrease with the duration of the entrepreneurial spell.

\section{Employer size}

We expect firms to be less concerned about the uncertainty of a candidate's fit in situations where the cost of replacing an employee who does not meet the performance expectations is lower (Kuhnen and Oyer, 2016). Therefore, we propose the effect of uncertainty on the wage penalty to be more pronounced when the entrepreneur is hired by firms that bear higher firing and replacement costs. While there might be several sources of firms' heterogeneity in the cost of non-performance, as we proceed empirically, we will exploit variation in the size of the new employer. There are several reasons why we would expect that larger firms bear lower costs. First, larger firms incur lower replacement costs (Kuhnen and Oyer, 2016). Finding a replacement for a worker who is revealed to be a poor match is costlier for small firms than for large firms because they often do not have dedicated HR departments or the ability to recruit from internal labor markets (Tate and Yang, 2015). Second, larger firms face relatively lower firing costs. In our empirical setting, the costs of firing a worker with a permanent contract mostly depend on his/her seniority at a firm - with a minimum of three months' salary, a sum that represents a much greater share of the total output for firms with only a 
handful of employees than for large multinationals. Third, the total productivity in large firms is less affected by the presence of an unproductive employee. Whereas in small firms, the marginal contribution of a worker is more directly associated with firm performance, ceteris paribus. Thus, the cost of non-performance is higher in smaller firms, independent of the occupation of the employee.

In conclusion, we hypothesize that the wage penalty is more severe for entrepreneurs who are hired by small employers than for those who are hired by large organizations.

To summarize, in the empirical analysis, we will test the following predictions:

H1: Entrepreneurs receive a wage penalty relative to observationally equivalent employees.

$\mathrm{H} 2$ : The wage penalty is more severe for entrepreneurs

(a) who were in the upper tail of the wage distribution,

(b) who exited quickly, and

(c) who are hired by smaller firms.

\section{Empirical Context}

This paper uses data drawn from the Belgian labor market. The Belgian labor market, unlike that of the US, is perceived to be highly rigid. According to the Organisation for Economic Co-operation and Development (OECD), Belgium ranks third in terms of worker protection against individual and collective dismissals, just behind Venezuela and China. These labor market frictions increase the costs of firing unsuccessful hires and thus make Belgium a particularly suitable context to test the role of uncertainty in hiring. Moreover, Zimmer (2012) observes that Belgium has a high mismatch between labor supply and demand, driven by a shortfall in the relative share of highly skilled job seekers and, conversely, a relatively high share of low-skilled labor supply, for which the demand is rather weak. These features of the Belgian labor market corroborate the appeal of this context to test our theory because it implies that concerns about a person's productivity will likely play an important role in the hiring process.

The Belgian business landscape is characterized by low rates of entrepreneurial entry and exit. In 2015, new businesses accounted for only 6.40 percent of the total share of all businesses, the lowest percentage in Europe. Belgium does fairly well in terms of its regulatory framework, market condi- 
tions, access to finance, and entrepreneurial capabilities (De Mulder and Godefroid, 2016), but it has poor contract enforcement (Calvino et al., 2016), high paid-in minimum capital requirements (Dreher and Gassebner, 2013), and a minimal entrepreneurial culture (De Mulder and Godefroid, 2016). One important factor that may hamper entrepreneurship in Belgium is the relatively high administrative burdens required to start a business : according to the OECD's Product Market Regulation Indicators Database, Belgium ranks among the 10 countries with the highest administrative burdens on startups.

At the same time, 71 percent of Belgian businesses survive their first three years, and 63 percent survive their first five years. ${ }^{1}$ While these numbers might suggest an above-average performance of Belgian entrepreneurs compared with those in other countries, they could also indicate low thresholds of performance (Gimeno et al., 1997) and low levels of experimentation (Landier, 2005; Manso, 2016), especially if combined with little growth. The findings of Geurts and Van Biesebroeck (2016) suggest the latter explanation. Using Belgian data, they show that de novo entrepreneurs contribute little to overall job creation, and much less than commonly believed based on official statistics.

The characteristics described above make the Belgian situation comparable to those in other Western European countries, such as France, Germany, Finland, and Sweden. Previous studies examining the returns from an entrepreneurial experience usually rely on data from relatively flexible labor markets and dynamic business environments, such as the US and Denmark (Kaiser and Malchow-Møller, 2011; Daly, 2015; Manso, 2016; Bruce and Schuetze, 2004; Williams, 2000). These contexts are characterized by a high tolerance for entrepreneurial experimentation and failure.

\section{Data and Methodology}

\section{Data source and construction of a matched sample}

We analyzed data on the Belgian labor market from the Data Warehouse Labor Market and Social Protection (DWH LM\&SP), maintained by the Crossroads Bank for Social Security (CBSS). The DWH LM\&SP is a linked administrative dataset that combines quarterly data from nearly 20 Belgian social security institutions, covering the full population of legal residents in Belgium. The data

\footnotetext{
${ }^{1}$ source: Eurostat Business demography statistics:http://ec.europa.eu/eurostat/statistics-explained/index.php/
} 
span all quarters between the first quarter of 2000 and the fourth quarter of 2015 and contain detailed information about individuals' demographics, employment status, and income.

The initial sampling frame consists of the population of full-time employees working in one job in wage employment in the first quarter of 2004, who either transitioned into entrepreneurship at some point between 2004 and 2015 (entrepreneurs) or who remained in wage employment for that period (employees). A person is assigned to the entrepreneurs' group if he/she is classified as selfemployed for at least four consecutive quarters between the second quarter of 2004 and the fourth quarter of 2015. CBSS classifies a person as self-employed if, on the last day of a given quarter, his/her main job is entrepreneurship and he/she is not registered as an employee. Relying on this classification ensures that individuals affiliated with more than one firm in the form of a start-up and wage work were excluded, as these hybrid transitions follows different dynamics (Folta et al., $2010)^{2}$

To make our sample comparable to those used in previous studies examining the determinants and outcomes of a spell of entrepreneurship (e.g., Failla et al., 2017; Kaiser and Malchow-Møller, 2011; Nanda and Sørensen, 2010; Sørensen, 2007) and to reduce the likelihood that the results might be attributable to confounding factors, we impose additional restrictions. First, we restrict the sample to individuals aged 22-49 in the first quarter of 2004 to eliminate biases attributed to left and right censoring. Second, we exclude those with entrepreneurship experience between 2000 and 2003 because the dynamics of serial entrepreneurship are likely to be distinct from those of first-time entrepreneurship (Westhead and Wright, 1998). Third, in line with previous studies (e.g., Nanda and Sørensen, 2010; Sørensen, 2007), we exclude individuals working in the primary sector in the first quarter of 2004. Fourth, to avoid missing observations for individuals moving out of the country at a certain point in time, we restrict the sample to individuals who continuously resided in Belgium between 2004 and 2015.

Identifying the potential wage cost of a spell of entrepreneurship poses an important inferential challenge, as transition into entrepreneurship is not random. Various studies have shown that individ-

\footnotetext{
${ }^{2}$ In unreported analyses, we verified that our results are robust with respect to the inclusion of hybrid entries and exits in and out of entrepreneurship. The results of this analysis are available upon request from the authors.
} 
uals self-select into entrepreneurship based on certain characteristics and incentives, such as a preference for non-pecuniary benefits (Hamilton, 2000) and a balanced skill set (Lazear, 2005). Thus, naive estimations of the outcomes would likely result in high model dependence and heavy reliance on extrapolation because of an insufficient overlap in covariate distribution (King et al., 2007; Stuart, 2010). To address potential biases caused by self-selection, we construct a matched sample of employees who are similar to the entrepreneurs on a range of observable characteristics. The fundamental counterfactual idea is that the wages of the matched employees represent the outcomes of the entrepreneurs had they not chosen to become self-employed. This method has been used to address issues of self-selection in previous studies measuring entrepreneurial outcomes (Campbell, 2013; Daly, 2015; Failla et al., 2017; Kaiser and Malchow-Møller, 2011; Manso, 2016)

We apply a combination of exact matching and propensity score matching (Rosenbaum and Rubin, 1983), particularly 1:1 nearest neighbor matching without replacement. An individual is considered as a good match to another individual who chooses to become entrepreneur if in the first quarter of 2004,1$)$ the individual is in the same age category, has the same gender, lives in the same region, works in the same industry, and has the same average daily wage; and 2) if their estimated propensity scores differ by no more than $0.002^{3}$. To ensure that the results are not peculiar to our matching algorithm, we also applied coarsened exact matching (Iacus et al., 2012). The results of this exercise are shown in Table A2 in the Appendix. The mean values for most of the variables of the coarsened exact matched sample are very similar to those obtained from the propensity score matching. Therefore, we do not expect that our results would change significantly if we had used the sample obtained from the coarsened exact matching ${ }^{4}$.

\footnotetext{
${ }^{3}$ The use of the specified distance also implies common support, i.e., there is a complete overlap in the distributions of the propensity scores between the entrepreneurs and employees in the matched sample. The chosen width is substantially smaller than the generally recommended caliper of 0.2 standard deviations of the linear propensity score (Austin, 2011).

${ }^{4} \mathrm{An}$ important set of robustness checks of the results is to verify that they are consistent across a variety of matching algorithms. Yet, data access restrictions limited our ability to perform such robustness tests. As such, we suggest this limitation as a direction for future research.
} 


\section{Matching variables}

In the matching procedure, we include a series of variables that previous studies have shown to be related to transitions into entrepreneurship and wage work. One advantage of including many different variables rather than a small set of predictors of convenience is that this minimizes potential bias due to the omission of an important confounder (Stuart, 2010). The matching variables were measured in the first quarter of 2004, i.e., right before the individual becomes at risk of becoming an entrepreneur.

As a starting point, we include several demographic variables. Most people start businesses when they are well into their thirties or older (Evans and Jovanovic, 1989). Second, entrepreneurs are more likely to be male (Manso, 2016). Therefore, we consider individuals to be a good match if they are in the same age category and of the same gender. Blanchflower and Meyer (1994) suggests that civil status affects the entrepreneurial entry choice. We include a civil status variable that distinguishes between individuals with or without partners and indicates the number of children for whom they are responsible, as well as variables capturing whether a person's partner has a job and his/her average daily wage. Furthermore, to control for potential structural geographical differences in labor market dynamics, we match individuals on the region (Flanders, Wallonia, and the Brussels Capital region) they were living in the first quarter of 2004.

We include a variable measuring the number of jobs a person held between 2000 and 2004 as a proxy for entrepreneurs being jacks-of-all-trades (Lazear, 2005) or having a preference for (job) variety (Åstebro and Thompson, 2011). We also include a measure of how many quarters a person was unemployed between 2000 and 2004 to capture differences in labor market experience.

Smaller firms spawn entrepreneurs at a higher rate, and entrepreneurs coming from small firms perform differently than those coming from large firms (Elfenbein et al., 2010; Parker, 2009). Additionally, wages and wage growth are higher in larger firms, on average (Oi and Idson, 1999). Therefore, we include an employer size variable, measured as the number of employees at the firm the individual was affiliated with in the first quarter of 2004. An indicator for whether a person is working in the public or private sector is also added, as the type of sector affects the likelihood of becoming 
an entrepreneur (Özcan and Reichstein, 2009). To control for potential differences in switching costs emerging from differences in firm- or industry-specific human capital (Becker, 1993; Neal, 1995), we included an individual's tenure at his/her current employer, as well as his/her tenure in his/her current industry.

Astebro et al. (2011) and Elfenbein et al. (2010) show that a person's position in the wage distribution is an important predictor of entrepreneurial entry. Therefore, two individuals were matched if they earned the same average daily wage in the first quarter of 2004. CBSS provides information about an individual's average daily wage per quarter, which is defined by

$$
\frac{(\text { Quarterly normal remuneration }+ \text { flat }- \text { rate remuneration })}{N r . \text { full }- \text { time remunerated days }}
$$

. All reported wages are gross wages and are provided by CBSS in classes of 10 euros. We also include a measure of an individual's annual wage growth to take into account potential negative wage shocks related to transitions into entrepreneurship.

Despite the wide range of covariates included in the matching procedure, no data are available on a person's education. Although this is a limitation of our study, we tried to minimize concerns about the confounding effects of unobserved ability by performing close matches on variables that are significantly correlated with ability, such as wage, wage growth, and time spent in unemployment.

\section{Quality of the matched sample}

Table A1 in the Appendix provides the summary statistics for the variables used in the matching process. Columns 1 to 3 show the summary statistics for the full sample prior to matching. The first column displays the average values for the entrepreneurs. The second column gives the corresponding values for the employees. The third column displays the standardized percentage bias ${ }^{5}$. One advantage of this balance diagnostic is that it is similar to an effect size (Rosenbaum and Rubin, 1985), which is preferred over the use of t-tests or p-values to assess balance (Stuart, 2010).

\footnotetext{
${ }^{5}$ The standardized percentage bias is the percentage difference of the sample means in the entrepreneurs' and employees' (full and matched) sub-samples as a percentage of the square root of the average of the sample variances of both groups (Rosenbaum and Rubin, 1985).
} 
Entrepreneurs are more likely to be male, between 25 and 34 years old in 2004, and to have a partner with entrepreneurship experience. They have a higher likelihood of working in the private sector, particularly in the fields of construction, wholesale, retail trade, real estate, or professional services. They are less likely to be employed in the public administration, defense, or education sectors. Entrepreneurs are much more likely to be employed in smaller firms, and they are more than 50 percent less likely to come from the largest firms $(\geqslant 1000$ employees). They also have a more varied job history, have lower tenure at their current employer, and spent more quarters in unemployment between 2000 and 2004. They have a slightly higher daily wage, but they do not differ from employees with regard to annual wage growth. Overall, these figures closely resemble those found in previous studies of entrepreneurship.

Columns 4 to 6 present the summary statistics for the entrepreneurs and employees after the matching procedure. Apart from perfectly balancing the variables on which exact matching was performed (age, region, industry, and daily wage), the matching process significantly improves balance on the remaining covariates: none of the variables has a standardized percentage bias greater than 2.3 percent in the matched sample, well below the 10 percent convention (Rosenbaum and Rubin, 1985). The pre-matching imbalances, which could influence the reliability of the estimates, have been removed. In total, we retain a matched sample of 64,946 individuals.

\section{Additional sample restrictions}

One shortcoming of relying on occupational data is that it does not provide information about the nature of the entrepreneurship spell. To mitigate concerns about necessity entrepreneurship, we restrict the analysis to matched pairs in which the entrepreneur transitions into entrepreneurship no later than four quarters after leaving paid employment (Non-necessity, column in Table 1). Therefore, individuals who enter entrepreneurship after a full year of unemployment or inactivity are excluded, as they might have become self-employed because of limited opportunities in the labor market. Similarly, as we are interested in entrepreneurs returning to the labor market, we only include entrepreneurs who return no later than four quarters after leaving entrepreneurship (Return).

To avoid issues of different pay schemes between full- and part-time or temporary jobs, we also 
restrict the sample to individuals who transition into entrepreneurship after leaving a full-time job and who re-enter the labor market via a full-time job (Full-time job). While this restriction leads to a significant drop in the number of observations, it allows us to obtain parameter estimates that are less likely to be biased because of the confounding effects of the different nature of remuneration between these types of jobs. However, this also urges caution in generalizing the results to workers who enter and/or exit entrepreneurship via part-time or temporary jobs.

Table 1 provides an overview of how the number of observations and the daily wage changed when we imposed these additional restrictions. In the final sample, we retain 2,735 entrepreneurs. The most significant drop in observations occurs when we restrict our sample to the entrepreneurs who return to wage employment within the sampling period. This is likely because a substantial share of the entrepreneurial spells in our data commenced some years after 2004 and, therefore, can be right censored.

[Insert Table 1 about here]

Because we lose a substantial share of individuals from the full matched sample when we impose the additional restrictions, we want to verify how the retained sample differs from the individuals who have been dropped after imposing these restrictions. In Table A3 in the Appendix, we compare the means of the retained and dropped sub-samples over a range of demographic- and employmentrelated variables in the first quarter of 2004. In terms of average daily wage, the two groups are equal and earn around 109 euros per day. Small differences exist in terms of age, region, and household position. Yet, the retained sample has significantly fewer women than men. Furthermore, the individuals in the retained sample are more likely to be blue-collar workers than white-collar workers. In terms of industry, we observe that there are more workers in the construction sector and few in healthcare and support services. Individuals in the retained sample held more jobs, on average, and had about three months less tenure with their employer. 


\section{Results}

\section{Descriptive analysis}

This study examines the relationship between a spell of entrepreneurship and the wages/wage growth of workers returning to paid employment. To measure the wage growth between the moment just before entering entrepreneurship and the moment of re-entering wage employment, we calculate the percentage of wage growth between the two periods and divide it by the duration of the intervening entrepreneurship spell. For the employees, we take the quarters of pre- and re-entry of their matched entrepreneur, so by construction, the spell lengths between both groups are equal.

[Insert Table 2 about here]

Table 2 provides the means and standard deviations of the employment-related variables for the entrepreneurs and matched employees in the last quarter before entry into entrepreneurship, the preentry quarter, and the first quarter in wage employment after exiting entrepreneurship. In the preentry quarter, entrepreneurs earn, on average, 127.63 euros per day, whereas the matched employees average 127.73 Euros. The difference is not significant, and it indicates that between the first quarter of 2004 (when the matching was performed) and the quarter of pre-entry, the wage trends of entrepreneurs and matched employees are equal. Yet, entrepreneurs have about four quarters less tenure with their employer, and they have worked for more employers. Furthermore, entrepreneurs are more likely to work for the smallest firms (1-9 employees). Therefore, it is important that we control for these factors in the regression analysis.

As Table 2 shows, at the quarter of re-entry, significant differences exist between entrepreneurs and the matched employees in terms of wage and wage growth. Entrepreneurs earn, on average, 136.63 euros per day, about 10.4 euros less than their matched counterparts. Entrepreneurs' estimated quarterly wage growth is 0.03 percent, 0.07 percentage points lower, or less than one third of the wage growth of the matched employees. Almost 82 percent of the entrepreneurs work for a different employer than the one they were working for pre-entry, compared with 23 percent of the matched employees. Similar to the quarter of pre-entry, there is a higher concentration of en- 
trepreneurs in small firms, and entrepreneurs are less likely to work for larger employers.

Figure 1 displays the distribution of the durations of the entrepreneurial spells. On average, an entrepreneur remains for around 14 quarters, or 3.5 years, in entrepreneurship (cf. Table 2), but the distribution of spell lengths is right skewed: almost 50 percent of the spells last between one and two years, and almost 30 percent last between three and four years. These findings confirm previous observations that entrepreneurial spells tend to be short (cf. Manso, 2016; Dillon and Stanton, 2017). In this study, however, we only take into account entrepreneurial spells that effectively end and not the full range of entrepreneurial spells. The average spell length is therefore underestimated.

[Insert Figure 1 about here]

\section{Tests against the data}

The descriptive analysis showed that entrepreneurs earn significantly less than comparable wage employees when returning to paid employment. In the theory section, we argued that this penalty can be attributed to the increased uncertainty about job applicants with an entrepreneurial background (H1). To further corroborate our claims, we now turn to examining how heterogeneity in the degree and costs of uncertainty influences the size of the wage penalty.

\section{Rank in the wage distribution}

The theory predicts that the wage penalty increases for entrepreneurs with a higher ability signal (H2a). To verify these claims, we start by estimating the following three equations:

$$
\begin{array}{r}
w_{i 0}=\alpha_{0}+\alpha_{E} \text { Entrepreneur }_{i}+\alpha_{X} X_{i 0}+\alpha_{I} I_{i 0}+\epsilon_{0} \\
w_{i 1}=\beta_{1}+\beta_{E} \text { Entrepreneur }_{i}+\beta_{W} W_{i 0}+\beta_{E W}\left(\text { Entrepreneur }_{i} * W_{i 0}\right)+\beta_{X} X_{i 1}+\beta_{I} I_{i 1}+v_{1} \\
\Delta w_{i}=\delta_{1}+\delta_{E} \text { Entrepreneur }_{i}+\delta_{W} W_{i 0}+\delta_{E W}\left(\text { Entrepreneur }_{i} * W_{i 0}\right)+\delta_{X} X_{i 1}+\delta_{I} I_{i 1}+\xi_{1}
\end{array}
$$

where $w_{i 0}$ and $w_{i 1}$ are, respectively, the natural logarithm of the average daily wage in the quarter of pre- and re-entry, and $\Delta w_{i}$ is the wage growth. Entrepreneur $r_{i}$ is a dummy variable that takes on the value of one if the individual belongs to the group of entrepreneurs. $X_{i 0}$ and $X_{i 1}$ are vectors containing the observed characteristics of individuals and their employers at the quarters of pre- and 
re-entry. Specifically, in each model, we account for a person's gender, age, position in the household, region, occupation, employer sector, industry, size, and the length of his/her entrepreneurship spell. $W_{i 0}$ represents the average daily wage at the quarter of pre-entry, in deciles, and functions as a proxy for workers' ability. To allow for a differential effect of entrepreneurial experience at the various levels of wage distribution, we also include the interaction effect Entrepreneur ${ }_{i} * W_{i 0} . I_{i 0}$ and $I_{i 1}$ represent quarter fixed effects at the time of pre- and re-entry.

Equation (1) counts as a robustness check. Conditional on a range of observables, no significant differences should exist in terms of wages between the entrepreneurs and matched employees before entrepreneurship. If there are, issues related to positive or negative selection into entrepreneurship could influence the results of the estimations of the wage and wage growth at the quarter of re-entry into the labor market. Potentially significant differences in the pre-entry quarter should therefore be taken into account when interpreting the coefficients of $w_{i 1}$ and $\Delta w_{i}$. As we are particularly interested in the possible differences in wage penalty between the top and the bottom of the wage and ability rank, we estimate Equation (1) via quantile regressions for the 10th, 25th, 50th, 75th, and 90th percentiles to ensure that no significant differences exist between entrepreneurs and paid workers at distinct points of the wage distribution. We estimate equation (2) and (3) with and without the interaction effects.

Table 3 displays the results of the quantile regressions of equation 1 and the OLS regressions of equations (2) and (3). ${ }^{6}$ Columns 1 to 5 report the results of the relationship between entering entrepreneurship and a person's wage in the last quarter of paid employment before transitioning to entrepreneurship at different points in the wage distribution. The results from the conditional analysis confirm those from the unconditional comparison of means (cf. Table 2): conditional on a variety of covariates, entrepreneurs do not earn significantly more or less before transitioning to entrepreneurship at any point in the wage distribution.

[Insert Table 3 about here]

\footnotetext{
${ }^{6}$ We also estimated a seemingly unrelated regression (SUR) system on the same set of equations to allow for crossequation error correlation. This did not alter the results.
} 
Columns 6 and 7 in Table 3 show the results for the wage in the quarter of re-entry into paid employment. We find that, conditional on the wage before entering entrepreneurship, entrepreneurs earn 5.7 percent less than their counterparts in the control group (column 6). Furthermore, when we include the interaction effect between the entrepreneur dummy and the pre-entry wage rank (column 7), the results indicate that the penalty is larger the more an entrepreneur earned before entering entrepreneurship. Figure 2 displays the predictive margins of the wage at re-entry for entrepreneurs and the matched employees. The dashed line indicates the estimated margins for the entrepreneurs; the solid line is for the matched employees. Entrepreneurs coming from the lower tail of the wage distribution (1st and 2 nd deciles) do not earn a lower wage than their employee counterparts, but the wage gap appears at the 5 th and is widest at the 9 th and 10 th deciles.

Columns 8 and 9 in Table 3 display the results for the predicted quarterly wage growth between the quarter of pre-entry into entrepreneurship and that of re-entry into paid employment. The results confirm the findings that entrepreneurs incur a wage cost when returning to the labor market. On average, their quarterly wage growth is around 0.6 percent lower per quarter (column 8 ). However, the entrepreneurs who come from the upper tails of the pre-entry wage distribution are punished the most. Figure 3 displays the predictive margins for the entrepreneurs and employees of the estimated regression in column 5 of Table 3. Entrepreneurs coming from the upper tail of the pre-entry wage distribution not only have significantly lower wage growth than their matched counterparts, but their wage growth is also negative. Entrepreneurs in the top decile of the wage distribution have a predicted quarterly wage loss of 1.8 percent.

[Insert Figures 2 and 3 about here]

In general, external job applicants are riskier hires than workers taking up a new job from inside the firm (Bidwell, 2011). Therefore, an important concern regarding these results is that they might be driven by the fact that most employees in the control group do not change employers at the time the matched entrepreneur returns to wage work, so we might pick up the effect of uncertainty about the productivity of new hires, in general, rather than uncertainty specifically related with entrepreneurial experience. To address this concern, we check the sensitivity of the wage penalty to a 
counterfactual of matched employees who change employers within a year from the quarter the entrepreneur re-enters wage work $(n=581)$. Figure 4 shows the quarterly wage growth for the sample in which the matched employee also changes jobs within the year the entrepreneur returns to wage work. The results are very close to those of the main analysis. If job changing per se were negatively associated with an individual's wage growth, we would expect a downward shift in the matched employee's wage growth plot. This is not the case. Therefore, our results do not appear to be driven by oversampling stayers in the control group.

\section{[Insert Figure 4 about here]}

\section{Length of the entrepreneurial spell}

We next examine if the wage penalty declines with tenure in entrepreneurship (H2b). To test this conjecture, we compare the differences in quarterly wage growth between entrepreneurs and their matched counterparts for entrepreneurs who exit quickly versus those who survive for a number of years. To do so, we estimate the following model:

$$
\begin{array}{r}
\Delta w_{i}=\theta_{1}+\theta_{E} \text { Entrepreneur }_{i}+\theta_{W} W_{i 0}+\theta_{D} D_{i}+\theta_{E W}\left(\text { Entrepreneur }_{i} * W_{i 0}\right) \\
+\theta_{E D}\left(\text { Entrepreneur }_{i} * D_{i}\right)+\theta_{W D}\left(W_{i 0} * D_{i}\right) \\
+\theta_{E W D}\left(\text { Entrepreneur }_{i} * W_{i 0} * D_{i}\right)+\theta_{X} X_{i 1}+\theta_{I} I_{i 1}+\psi_{1}
\end{array}
$$

The parameters included in equation 4 are those of equation 3, but we add a three-way interaction effect between the entrepreneur dummy, a person's position in the wage distribution $W_{i 0}$, and the duration of his/her entrepreneurial spell $D_{i}$ (or his/her matched counterpart's spell for the control group).

Table 4 displays the marginal effects obtained from the OLS regression of Equation 4. Each cell represents the difference in wage growth between the entrepreneurs and the matched employees for a certain spell duration (all spells, 1-2, 3-4, 5-6, and 7+ years) at a certain level of pre-entry wage (1st, 2nd, 5th, 9th, and 10th deciles). The results show that entrepreneurs coming from the lowest pre-entry wage deciles (1st and 2nd) never incur a penalty. However, for those who earned a relatively high wage before entering entrepreneurship (5th, 9th, and 10th deciles), the wage penalty is 
most pronounced when they exit in the first two years after entry, and it gradually declines over time. After five years of survival in entrepreneurship, no wage growth difference can be observed between entrepreneurs and their matched counterparts at any level of pre-entry wage.

[Insert Table 4 about here]

\section{Employer size}

So far, we have observed that employees from the top of the wage distribution are penalized for attempting entrepreneurship, but only if they exit quickly. We now turn to our final prediction, namely that the penalty is larger for entrepreneurs hired by small employers $(\mathrm{H} 2 \mathrm{c})$.

To examine whether entrepreneurs are more penalized in small firms, we regress the quarterly wage growth on a triple interaction term between the entrepreneur dummy, the pre-entry wage (deciles), and a small firm dummy, which captures all firms with fewer than 20 employees. We also include a variable measuring the size of the employer at the quarter of pre-entry. In our data, the size of the employer before and after entrepreneurship is positively correlated, indicating that entrepreneurs who worked in small (large) firms before entrepreneurship are likely to work in small (large) firms after entrepreneurship, so adjusting for pre-entry employer size minimizes concerns that the results might be driven by wage differences between small and large firms before entrepreneurship. Additional control variables that are equal to those in Equation 4 are also included. In doing so, we can compare the wage growth across different wage deciles between entrepreneurs moving to small (large) firms against employees working in small (large) firms. As we only observed a penalty for short spells, we restrict the analysis to entrepreneurs returning to wage work within four years.

Table 5 displays the marginal effects obtained from the OLS regression. Each cell represents the difference in wage growth between entrepreneurs and the matched employees, respectively, for small and large employers at a certain level of the pre-entry wage (1st, 2nd, 5th, 9th, and 10th deciles). The results show that the penalty for former entrepreneurs is roughly the same in small and large firms for individuals in the lower and the median deciles of the pre-entry wage distribution. However, large discrepancies between small and large firms occur for those who earned relatively more 
before entering entrepreneurship: entrepreneurs coming from the top wage decile prior to entry into entrepreneurship and who find employment at a large firm after their entrepreneurial spell have an estimated 1.4 percentage points lower quarterly wage growth than similar employees in large firms without entrepreneurial experience. For entrepreneurs moving back to small firms, this penalty is more than three times larger; the estimated quarterly wage growth is 4.7 percentage points less for entrepreneurs coming from the top of the wage distribution compared with employees coming from the top of the distribution.

\section{[Insert Table 5 about here]}

A possible alternative explanation for these findings is that entrepreneurs who move back to small firms are of lower ability than those who find employment at a large firm. To test this possibility, we regress the entrepreneurial performance of the group of entrepreneurs on the probability of joining a small firm. The individuals' entrepreneurial performance is measured by their average yearly earnings during their entrepreneurial spell. ${ }^{7}$ We would expect a negative relationship between entrepreneurial performance and the probability of joining a small firm if entrepreneurs of lower ability are more likely to join small firms after they fail. We display the results using both the raw entrepreneurial earnings and the log of the entrepreneurial earnings, as the measure is highly skewed and hence the results may be driven by this feature of the variable.

\section{[Insert Table 6 about here]}

The results of the regressions of entrepreneurship earnings and $\ln$ (average entrepreneurship earnings $)^{8}$ on the probability of joining a small firm after entrepreneurship are reported in columns 1 and 2 of Table 6 . The coefficients on entrepreneurial earnings are close to and not statistically significantly different from zero. Therefore, we find no evidence that entrepreneurial ability influences the probability of moving to a small or large employer after entrepreneurship.

\footnotetext{
${ }^{7}$ We ran the same regressions only using the last reported earnings before exiting entrepreneurship. The results remain the same.

${ }^{8} 291$ entrepreneurs reported only zero earnings during their entrepreneurship spell. Therefore, they are dropped in the regression, in which we use the log-transformation of the earnings.
} 
Finally, we examine one situation in which uncertainty around an entrepreneur's future productivity is presumed to be absent, i.e., when the entrepreneur goes back to the same firm he/she worked for before entrepreneurship. In this case, employers can rely on the revealed worker's productivity during the first employment period rather than on the noisy signal of the entrepreneurial spell. We regress the quarterly wage growth on a triple interaction term between the entrepreneur dummy, a dummy indicating whether a worker changed employers between the pre- and re-entry quarters, and the worker's position in the wage distribution. We restrict the sample to the entrepreneurs (and their matched counterparts) who returned to wage employment within four years.

Figure 5 displays the marginal effects of a spell of entrepreneurship for the workers in the top decile of the wage distribution, split based on whether or not they changed employers. The left bar shows the difference in wage growth between the entrepreneurs and employees who work for the same employer in the pre- and re-entry quarters (employer change $=$ no). The right bar shows the difference in wage growth between the entrepreneurs and employees who move to a different employer. The results show that entrepreneurs who return to the same employer as before entrepreneurship do not incur a penalty compared with employees who work consecutively for the same employer, whereas entrepreneurs who move to a different employer incur a significant penalty compared with employees who have switched employers. These results corroborate our theoretical claims, as they show that the penalty occurs only in the presence of information asymmetries between job applicants and prospective employers.

[Insert Figure 5 about here]

\section{Robustness Checks}

\section{Sensitivity of the wage penalty to sample restrictions}

In an attempt to buttress the likelihood that we are capturing the direct relationship between a spell of entrepreneurship and future wages, we took steps that further reduce the influence of confounding factors. We did so by imposing restrictions on the sample of entrepreneurs who return to the wage sector (Return) by a) not including necessity entrepreneurs and b) only including entrepreneurs who 
entered entrepreneurship from and exited entrepreneurship to a full-time job. We now relax these restrictions to assess how sensitive our results are to these modeling decisions.

Full matched sample. We estimate the quarterly wage growth of all entrepreneurs and their matched counterparts who, at some point during the sample period, re-enter wage work after a spell of entrepreneurship $(17,208$ out of 32,473$)$, regardless of the time in unemployment or out of the labor force before and after entrepreneurship, and including part-time and temporary workers. Figure A1 in the Appendix shows the results. The pattern of the wage penalty is close to that of the restricted sample used in the main analysis (Figure 3). Yet, there is now a significant wage premium for entrepreneurs coming from the lowest wage decile, as well as a stronger penalty for the stars. The stronger wage penalty suggests that our estimates for the stars observed in the restricted sample are conservative. The wage premium is explained by the next exercise.

Relaxing full-time job. We now turn to relaxing the full-time job restriction. About 24 percent of the entrepreneurs re-enter into a part-time job, compared with 10 percent in the control group. As CBSS calculates the average daily wage for part-time jobs as if the person had worked a full-time week of 38 hours, any structural differences in hourly remuneration between these different types of contracts will bias the results. Figure A2 shows the results only for the entrepreneurs who re-enter into a part-time job and their matched counterparts $(n=4,166)$. We find results similar to the full sample (Figure A1) but different from the restricted sample (Figure 3): there is a significant wage premium for those who earned little before entering entrepreneurship, and a stronger penalty for the stars. This might be an indication of an hourly wage premium (penalty) for low-paid (high-paid) part-time jobs compared with similar full-time jobs. Therefore, it appears that the wage premium found in the full sample can be explained by the part-time job measurement error. To further investigate whether the premium at the left tail is driven by part-time workers, we look at a third category of job contracts, i.e., temporary contracts, which include all short-term and irregular contracts, mostly temporary and seasonal work. About 19 percent of the entrepreneurs re-enter into such a temporary job, although these are mostly entrepreneurs coming from the lowest wage deciles. Figure A3 displays the results for these entrepreneurs and matched employees $(n=3,276)$. For the lowest wage 
deciles, the results are similar to those of the restricted sample, further suggesting that the wage premium in the full sample is driven by the measurement error associated with taking on a part-time job. For the stars, the estimate of the wage penalty is much larger than before, but it also very noisy, as only 24 individuals from the 10th wage decile re-enter into a temporary job.

Relaxing non-necessity. We now relax the non-necessity restriction at both entry in entrepreneurship and re-entry into wage work to see whether including necessity entrepreneurs alters our estimates. Figure A4 illustrates the estimates of the wage growth for the sample of entrepreneurs who enter entrepreneurship after more than one year of unemployment or out of the labor force (necessity entry are 8.4 percent of all entries). These individuals might enter entrepreneurship because of limited outside options. The figure shows a similar pattern as the restricted sample with a slightly stronger penalty for stars. Finally, we estimate the wage growth for the sample of entrepreneurs who re-enter wage work after more than one year in unemployment or out of the labor force (necessity exit are13 percent of all exits). These entrepreneurs might experience difficulties in finding a suitable job. Figure A5 shows that the wage growth pattern mimics that of the restricted sample, but estimates at the top are very noisy because of few stars experiencing a necessity exit.

Overall, this exercise shows that our results are robust to different sample specifications. The estimates of the wage penalty for stars appear rather conservative in the restricted sample we use for the main analysis, as the penalty for stars observed in these larger samples appears even stronger.

\section{Sensitivity of the wage penalty compared to the matched group}

Counterfactual of movers in the year of entry into entrepreneurship. In the foregoing analyses, we already verified that our main results are not driven by the confounding effects of the uncertainty of hiring external job candidates, in general (cf. Figure 4). To further strengthen the argument that our results are not driven by the potential negative effects of job changing per se, we repeat this exercise for the sample of entrepreneurs and matched employees who change employer within one year from the quarter the entrepreneur enters self-employment $(n=488)$. Figure A6 displays the predicted wage growth at different levels of the wage deciles for this sample. We find that the estimated wage penalty is more compressed at the top deciles than in the full sample, although it is still significant 
$(\mathrm{p}<0.05)$. The smaller penalty is caused by an upward shift in the estimated wage growth of the entrepreneurs coming from the top of the wage distribution, rather than by a downward shift in the wage growth of the control group. This evidence is inconsistent with the concern that movers might have lower wage growth. We further investigate the origins of the smaller penalty for stars compared with the main control group by comparing entrepreneurs who have a job-changing matched counterpart at entry into entrepreneurship with those who do not. The results are displayed in Table A4 (columns 2 to 3). Entrepreneurs with a mover matched counterpart have a significantly lower preentry wage than those without. This is not surprising, as star employees are less likely to move but, conditional on moving, are more likely to start a company (e.g., Campbell et al., 2012); this is also confirmed in our data. Therefore, using a counterfactual of movers means shifting the pre-entry wage distribution to the left. As a result, the smaller penalty in the top decile corresponds to a lower decile (i.e., 9th) in the main control group, which further strengthens our key result.

Counterfactual of not yet entrepreneurs. A fundamental assumption throughout this study is that the wage trend of entrepreneurs would have been parallel to that of the matched employees after entering entrepreneurship had they not become entrepreneurs. Although we matched the two groups on their wages in 2004 and the wage trends between 2000 and 2004, and a comparison of the wages at the pre-entry quarter showed no significant differences in wage growth, this assumption might still possibly be violated on the basis of unobservables. Certain unobservable traits related to selecting into entrepreneurship and into lower-paying firms (e.g., Elfenbein et al., 2010) may lead to a downward bias in the estimate of the negative wage growth for the entrepreneurs. To address this possibility, we exploit the variation in timing of entry and exit out of entrepreneurship. Specifically, we compare the wage growth of a group of entrepreneurs who exit entrepreneurship and reenter wage employment no later than the first quarter of 2011 with the wage growth of a randomly selected group of entrepreneurs who did not enter entrepreneurship before the second quarter of 2011 and who always stayed in wage employment between the first quarter of 2004 and the first quarter of $2011^{9}$. To estimate the wage growth of the second group of not yet entrepreneurs, we duplicate

\footnotetext{
${ }^{9}$ This makes the group of not yet entrepreneurs similar to our original control group of employees who always stay in wage employment between the first quarter of 2004 and the last quarter of 2015.
} 
the pre- and re-entry quarters of the individuals in the first group and calculate the wage growth in between these two quarters by using the formula explained in section . Figure A7 shows the wage growth of the entrepreneurs who re-enter wage work before or at the first quarter of 2011 and of the group of not yet entrepreneurs $(n=2,476)$. The results display a pattern that is strikingly similar to the ones shown before. Compared with workers who are about to become entrepreneurs but are still employed, former entrepreneurs, on average, are penalized, and the wage penalty is most severe for stars. These findings bolster the claim that our results are not driven by unobservable traits shared by current, nascent, and former entrepreneurs.

\section{Alternative Explanations}

Previous research in labor economics and entrepreneurship suggests a few potential explanations for why entrepreneurs may be penalized when returning to wage work. We describe these below and investigate their potential to offer alternative interpretations for our set of empirical findings.

\section{Human capital depreciation}

The observed wage penalty of entrepreneurs is consistent with models of human capital depreciation (Mincer and Ofek, 1982), either because former entrepreneurs' job-, firm-, or sector-specific skills atrophy during their spell of entrepreneurship (Williams, 2000) or because they lose out on valuable on-the-job training opportunities (Koellinger et al., 2015; Mincer and Ofek, 1982). The penalty for employees from the right tail of the wage distribution would then result from a higher atrophy rate for occupations that require high ability (Polachek, 1981). The most intuitive implication of these models is that the penalty should increase with tenure in entrepreneurship, if we assume that the depreciation rate is positive. However, the empirical evidence in Table 4 shows the opposite: the wage penalty diminishes with time in entrepreneurship. Moreover, human capital depreciation would imply a penalty even for entrepreneurs returning to their previous employer, which is inconsistent with our results (Figure 5). 


\section{Expected job mismatch}

A symmetric explanation suggests that the human capital entrepreneurs develop is specific to that setting and is therefore not transferable to the wage sector. This argument has roots in the jack-ofall-trades theory, which predicts that entrepreneurs possess generalist skills, but employers value specialist skills (Lazear, 2005). Accordingly, the employer considers the candidate's choice to become entrepreneurs as a signal of potential skill mismatch and reacts by discounting the offered wage.

While mismatches are often interpreted in terms of skills, employers may also expect a mismatch between individual preferences and firm attributes (Jackson, 2013). Entrepreneurial preferences, such as tastes for autonomy (Hamilton, 2000), variety (Åstebro and Thompson, 2011), and risk (Fairlie, 2002), are at odds with the organizational culture of established firms (Özcan and Reichstein, 2009). As entrepreneurship is a choice, employers may discriminate against entrepreneurs based on an anticipated mismatch, a phenomenon more broadly known as taste-based discrimination (Koellinger et al., 2015). A straightforward prediction of this mechanism is a homogeneous penalty for all entrepreneurs, which contrasts with the significant heterogeneous penalties we find (Table 3).

In practice, however, established firms vary in the extent to which they mimic the organizational setting of start-ups. Most notably, small firms are closer to start-ups; both require a broader, balanced skill set, compared with large firms, which require narrowly defined and specialized jobs (Sørensen, 2007). Accordingly, a previous study suggests a higher transferability of human capital between small firms and start-ups (e.g., Elfenbein et al., 2010). Moreover, small firms appear as an attractive setting for entrepreneurial employees, also based on preference matching (Parker, 2009). These arguments predict a stronger penalty for entrepreneurs who join large firms because of the higher odds of job mismatch. Yet, the empirical evidence reported in Table 5 indicates a lower penalty in large firms.

Finally, there are organizational settings that mimic not only entrepreneurship but also occupations. Managers tend to have generalist skills (Lazear, 2012), and CEOs with generalist skills are paid more (Custódio et al., 2013). Therefore, the loss of human capital upon re-entering the wage sector is expected to be lower for those entrepreneurs hired in managerial positions. If we assume 
that entrepreneurs from the top tail of the wage distribution before entering entrepreneurship are more likely to hold managerial positions ex-post, then we would expect a weaker penalty for star employees. However, this is inconsistent with our key finding that stars are more penalized.

\section{Stigma of failure}

While the job mismatch rationale hinges on the information signal of entry into entrepreneurship, the stigma of failure explanation relies on the notion that (quickly) exiting out of entrepreneurship holds signaling value. With only limited information regarding job applicants' productivity, recruiters are likely to rely on generalization and stereotypes on the basis of observable characteristics: "most selfemployed applicants have failed, and this is probably one of them" (Koellinger et al., 2015, p 148.). These generalizations are at the origins of statistical discrimination (Altonji and Pierret, 2001). The labor market may hold the impression that entrepreneurs' ability is tightly coupled with the quality of their venture and that entrepreneurial earnings are tied to start-up performance. Therefore, a quick exit may signal firm failure and, in turn, poor ability. This explanation implies a homogeneous wage penalty across entrepreneurs, which is inconsistent with our heterogeneous effects (cf. Table 3).

\section{Sorting}

So far, we have discussed demand-side candidate explanations, and, thus, we have implicitly assumed that the lower returns of entrepreneurs are the outcome of an adverse labor market treatment. However, there might be room for supply-side alternative mechanisms based on entrepreneur sorting behaviors. Entrepreneurs may sort into firms that pay them a lower salary in exchange for non-pecuniary benefits, as the theory of compensating differentials predicts (Rosen, 1986). Nonpecuniary benefits are well recognized to be particularly valuable for entrepreneurs (Hamilton, 2000). This explanation offers different testable implications based on whether the preference for nonpecuniary incentives is the result of the entrepreneurship treatment or of innate traits.

A treatment effect that changes individual preferences would predict a more severe pay cut for entrepreneurs with longer entrepreneurial spells. The preference for non-pecuniary over pecuniary benefits becomes stronger the longer the time in entrepreneurship. Reinforcing this mechanism, the 
larger the non-pecuniary benefits, the lower the performance threshold, which contributes to delay exit (cf. Gimeno et al., 1997). Again, this prediction is contradicted by the evidence in Table 4.

Individuals with innate preferences for non-pecuniary benefits may sort into firms that mimic the entrepreneurial setting, such as small firms that offer, on average, lower salaries. If innate unobserved preferences drive our results, then we should observe a lower penalty when we use as counterfactual the group of not yet entrepreneurs. Assuming that this control group shares the same innate preferences as the group of former entrepreneurs is reasonable. However, the results displayed in Figure A7 do not support the hypothesis that our findings are driven by differences in innate preferences between entrepreneurs and employees.

\section{Labor market frictions}

An alternative explanation for why entrepreneurs who were star employees are penalized more severely could be that entrepreneurs coming from high-paid jobs have difficulties finding a similar position when they return to the labor market. However, this is unlikely to be the case. It is well established that the unemployment rate is highest among less able workers, which implies that higher-ability workers can more easily find jobs. Moreover, in a recent paper, Lazear et al. (2018) show that the vacancy rates are highest for high-paying, high-quality jobs, as high-ability individuals are more flexible and can do a wide variety of jobs, whereas low-ability workers are not able to perform in high-quality positions. An unreported analysis on our own data confirms that stars are less likely to exhibit unemployment spells upon returning to the wage sector.

Finally, it is possible that adverse selection out of entrepreneurship might partly drive the results. In others words, the penalty may occur because employers offer lower wages, assuming that mainly low-ability entrepreneurs return to paid employment. However, the possibility of adverse selection is difficult to reconcile with the finding of an increasing penalty for entrepreneurs with higher wages before entrepreneurship. Suppose that prospective employers do not observe the preentrepreneurship signals but only ask for details about current earnings and entrepreneurship performance, and this information asymmetry can induce adverse selection. While prospective employers are less informed than prospective employees, they are not uninformed because pre-entrepreneurial 
wages and entrepreneurship earnings are correlated. In this case, we would expect to see entrepreneurs with low pre-entrepreneurship wages only accepting jobs for which they are unqualified. Knowing this, however, employers would impose a greater penalty on job applicants whose observable signals are low. Our main finding that the penalty is higher when pre-entrepreneurship wages are high seems inconsistent with the presence of significant adverse selection effects.

In conclusion, the above discussion suggests that while each of these alternative mechanisms appears to be consistent with some of the findings, their implications are inconsistent with the full set of empirical evidence presented in this paper. Thus, our uncertainty-based model seems the most coherent explanation behind our overall empirical patterns.

\section{Concluding Remarks}

\section{Discussion}

The empirical literature documents a negative relationship between a spell of entrepreneurship and subsequent wages, but it remains largely silent about the origins of this adverse treatment. This study advances and tests a theory that explains why a spell of entrepreneurship negatively affects individuals' wages upon returning to the wage sector.

Building on both the entrepreneurship and labor economics literatures, we proposed that an intermittent spell of entrepreneurship is a noisier signal about expected productivity in future wage work than a continuous career in paid employment, and that this uncertainty will negatively affect entrepreneurs' future wages when they re-enter the labor market. From this theoretical framework, we derive a number of testable predictions. Entrepreneurs are expected to receive a lower wage than observationally equivalent employees because of their higher risk of non-performance on the job. The wage penalty is more severe for entrepreneurs (1) who were in the upper tail of the wage distribution prior to the entrepreneurial spell, (2) who exited quickly, (3) and who are hired by smaller firms because of these firms' higher costs of handling hiring risks.

We test these predictions by using a new dataset of matched entrepreneurs and employees from Belgium, covering all quarters between 2000 and 2015. We obtain a number of results that strongly support the proposed mechanism and none that leads us to reject it. First, we find that entrepreneurs, 
on average, are penalized, but the penalty is more severe for those coming from the right tail of the wage distribution and absent for those who earned a relatively low wage before entrepreneurship. Second, the penalty for stars disappears if entrepreneurs survive for five or more years, in line with the intuition that uncertainty about a signal resolves over time. Third, large firms penalize less, in line with the notion that large firms bear lower replacement costs in case of a bad hire. Finally, entrepreneurs returning to their previous employer are not penalized, consistent with the information value of the signal being close to zero. Our results are robust to different counterfactuals and sampling restriction strategies. Moreover, we sort out the most salient competing explanations, which further reinforce the validity of our theory.

Some limitations might affect the interpretation and generalizability of the findings. First, the matching algorithm will produce biased outcomes if the transition into entrepreneurship is related to unobservable factors not captured in the model used to estimate the propensity score. To mitigate this possibility, we have matched entrepreneurs and employees on an extensive range of variables. Furthermore, the findings from a robustness check in which we compare former entrepreneurs' wages with those of employees who will become entrepreneurs in the future in our sample do not indicate that our results are biased by the unobservable traits and preferences shared by all entrepreneurs and which might correlate with their wage. However, the possibility remains that we cannot fully control for unobserved heterogeneity. Second, the external validity of the results to the broader population of entrepreneurs and employees could be affected by the matching approach used in the paper. As a robustness check, we also performed a coarsened exact matching (Iacus et al., 2012). The output suggests that the results are not peculiar to our matching algorithm ${ }^{10}$. Moreover, the set of tests showing the robustness of our findings to relaxations of several sampling restrictions at least partially mitigates concerns of external validity, suggesting that the key results can be extrapolated to the broader population of entrepreneurs. Finally, the Belgian business landscape is characterized by low entrepreneurial dynamism, i.e., relatively low entry and exit, and by high labor market frictions

\footnotetext{
${ }^{10}$ An additional robustness test would be to examine if the results are consistent in an $\mathrm{n}: 1$ matched sample in order to verify if the findings are not attributable to the idiosyncratic characteristics of the individuals in the current sample. Unfortunately, data access restrictions prevented us from performing such analyses.
} 
that reduce the value of experimentation. Therefore, a potential avenue for future research is to verify whether the results can be replicated in more dynamic entrepreneurial contexts and flexible labor markets, such as those of the US and Scandinavian countries.

\section{Implications}

The findings also have implications for practice. It has almost become a doctrine in practitioners' entrepreneurship community (e.g., incubators) that failing fast is divine, as entrenched in the lean start-up movement. The idea is to avoid the sunk cost effect which may cause individuals to pursue opportunities even if the initial evidence indicates that the opportunity is not promising in its current form. This paper shows that outside option career considerations may question the attractiveness of failing rapidly. We suggest that high-ability entrepreneurs may consider the pivot option of the lean start-up as more desirable than the fast fail option, in which they fine-tune and adjust the business to better fit the market, allowing them to sustain the business and avoid the wage penalty.

Our findings also have implications for policy makers. First, the uncertainty in hiring entrepreneurs suggests that employers would value probationary contracts that offer the option to learn about the upside potential of these risky workers at a limited cost. As it is usually difficult for employers to poach star employees from other firms, hiring them from entrepreneurship via probationary contracts might prove an attractive recruitment strategy ${ }^{11}$. This would persuade employers not to disregard a pool of applicants with high potential, including the possible valuable skills gained in entrepreneurship (Campbell, 2013). Second, our result that the wage penalty declines with tenure in entrepreneurship might be consistent with the tendency of underperforming ventures to delay exit (e.g., Failla et al., 2017). Again, more flexibility in the use of probationary arrangements could also contribute to alleviating this labor market friction and allow employers to rely on the observed productivity during the probation period, rather than on noisy signals of entrepreneurial performance, such as survival. This would in turn increase the value to experiment without the risk of getting stuck. Third, our evidence that stars are penalized after short spells of entrepreneurship adds to the debate about the need

\footnotetext{
${ }^{11}$ This implication is particularly intriguing considering a reform in Belgium in 2014 that abolished this type of contract.
} 
for more entrepreneurial quality or quantity, which has recently shifted toward quality (e.g., Guzman and Stern, 2017; Belenzon et al., 2017). On the one hand, we caution highly paid employees against using entrepreneurship as an experimentation device (e.g., Kerr et al., 2014), as it bears the risk of a substantial wage penalty; on the other hand, we encourage workers with low ability signals to test the entrepreneurial waters. Overall, this paper improves our understanding of the costs associated with policy measures that promote experimentation with entrepreneurial ideas.

\section{Acknowledgements}

We thank the Editor and two anonymous referees for their valuable comments and suggestions. We also thank the participants at EPFL, DRUID, the annual meeting of the Academy of Management, the ZEW Conference on the Dynamics of Entrepreneurship, and the SMS special conference in Frankfurt for their insightful comments. We gratefully acknowledge the financial support of the Flemish Science Foundation. 


\section{References}

Abel, M., Burger, R., and Piraino, P. (2017). The Value of Reference Letters. . The World Bank Policy Research Working Papers, Available at: https://doi.org/10.1596/1813-9450-8266.

Agan, A. and Starr, S. (2018). Ban the Box, Criminal Records, and Racial Discrimination: A Field Experiment. The Quarterly Journal of Economics, 133(1):191-235.

Aksaray, G. and Thompson, P. (2017). Density Dependence of Entrepreneurial Dynamics: Competition, Opportunity Cost, or Minimum Efficient Scale? Management Science, 64(5):2263-2274.

Altonji, J. G. and Pierret, C. R. (2001). Employer Learning and Statistical Discrimination. The Quarterly Journal of Economics, 116(1):313-350.

Amit, R. and Cockburn, I. M. (1995). Opportunity Costs and Entrepreneurial Activity. Journal of Business Venturing, 10(2):95-106.

Åstebro, T. and Thompson, P. (2011). Entrepreneurs, jacks of all trades or hobos? Research Policy, 40(5):637-649.

Astebro, T. B., Chen, J., and Thompson, P. (2011). Stars and Misfits: Self-Employment and Labor Market Frictions. Management Science, 57(11):1999-2017.

Austin, P. C. (2011). Optimal caliper widths for propensity-score matching when estimating differences in means and differences in proportions in observational studies. Pharmaceutical Statistics, 10(2):150-161.

Autor, D. H. and Scarborough, D. (2008). Does Job Testing Harm Minority Workers? Evidence from Retail Establishments. Quarterly Journal of Economics, 123(1):219-277.

Baptista, R., Lima, F., and Preto, M. T. (2012). How former business owners fare in the labor market? Job assignment and earnings. European Economic Review, 56(2):263-276.

Barach, M. and Horton, J. J. (2017). How Do Employers Use Compensation History? Evidence from a Field Experiment. . Working Paper, Available at: https://papers.ssrn.com/sol3/papers.cfm?abstract_id=2943034.

Barron, J. M., Bishop, J., and Dunkelberg, W. C. (1985). Employer Search: The Interviewing and Hiring of New Employees. The Review of Economics and Statistics, 67(1):43.

Becker, G. (1993). Human Capital: A Theoretical and Empirical Analysis, with Special Reference to Education. The University of Chicago Press, 2nd edition.

Belenzon, S., Chatterji, A. K., and Daley, B. (2017). Eponymous entrepreneurs. American Economic Review, 107(6):1638-1655.

Bertrand, M. and Mullainathan, S. (2004). Are Emily and Greg More Employable than Lakisha and Jamal? A Field Experiment on Labor Market Discrimination. The Quarterly Journal of Economics, 94(4):991-1013.

Bidwell, M. (2011). Paying More to Get Less. Administrative Science Quarterly, 56(3):369-407. 
Blanchflower, D. G. and Meyer, B. D. (1994). A longitudinal analysis of the young self-employed in Australia and the United States. Small Business Economics, 6(1):1-19.

Borjas, G. J. and Goldberg, M. S. (1978). Biased screening and discrimination in the labor market. American Economic Review, 68(5):918-922.

Bruce, D. and Schuetze, H. J. (2004). The labor market consequences of experience in selfemployment. Labour Economics, 11(5):575-598.

Cahn, C., Girotti, M., and Landier, A. (2017). Entrepreneurship and Information on Past Failures: A Natural Experiment. Banque de France Working Paper No. 644. Available at SSRN: https://ssrn.com/abstract=3046456.

Calvino, F., Criscuolo, C., and Menon, C. (2016). No Country for Young Firms? Technical Report 29, OECD Science, Technology and Industry Policy Papers.

Campbell, B. A. (2013). Earnings Effects of Entrepreneurial Experience: Evidence from the Semiconductor Industry. Management Science, 59(2):286-304.

Campbell, B. A., Ganco, M., Franco, A. M., and Agarwal, R. (2012). Who leaves, where to, and why worry Employee mobility, entrepreneurship and effects on source firm performance. Strategic Management Journal, 33(1):65-87.

Chatterji, A. K. (2009). Spawned with a silver spoon? Entrepreneurial performance and innovation in the medical device industry. Strategic Management Journal, 30(2):185-206.

Chatterji, A. K., de Figueiredo, R. J. P., and Rawley, E. (2016). Learning on the Job? Employee Mobility in the Asset Management Industry. Management Science, 62(10):2804-2819.

Custódio, C., Ferreira, M. A., and Matos, P. (2013). Generalists versus specialists: Lifetime work experience and chief executive officer pay. Journal of Financial Economics, 108(2):471-492.

Daly, M. (2015). The long term returns of attempting self-employment with regular employment as a fall back option. Labour Economics, 35:26-52.

De Mulder, J. and Godefroid, H. (2016). How to stimulate entrepreneurship in Belgium? Economic Review, (ii):63-80.

DeVaro, J. and Waldman, M. (2012). The Signaling Role of Promotions: Further Theory and Empirical Evidence. Journal of Labor Economics, 30(1):91-147.

Dillon, E. and Stanton, C. (2017). Self-Employment Dynamics and the Returns to Entrepreneurship. National Bureau of Economic Research Working Paper Series, No. 23168.

Dixit, A. (1992). Investment and Hysteresis. Journal of Economic Perspectives, 6(1):107-132.

Dreher, A. and Gassebner, M. (2013). Greasing the wheels? The impact of regulations and corruption on firm entry. Public Choice, 155(3-4):413-432. 
Eggers, J. P. and Song, L. (2015). Dealing with Failure: Serial Entrepreneurs and the Costs of Changing Industries Between Ventures. Academy of Management Journal, 58(6):1785-1803.

Elfenbein, D. W., Hamilton, B. H., and Zenger, T. (2010). The Small Firm Effect and the Entrepreneurial Spawning of Scientists and Engineers. Management Science, 56(4):659-681.

Evans, D. S. and Jovanovic, B. (1989). An Estimated Model of Entrepreneurial Choice under Liquidity Constraints. Journal of Political Economy, 97(4):808-827.

Failla, V., Melillo, F., and Reichstein, T. (2017). Entrepreneurship and employment stability Job matching, labour market value, and personal commitment. Journal of Business Venturing, 32(2):162-177.

Fairlie, R. W. (2002). Drug Dealing and Legitimate Self-Employment. Journal of Labor Economics, 20(3):538-537.

Falk, A. and Zimmermann, F. (2017). Consistency as a Signal of Skills. Management Science, 63(7):2197-2210.

Folta, T. B., Delmar, F., and Wennberg, K. (2010). Hybrid Entrepreneurship. Management Science, 56(2):253-269.

Freeman, J., Carroll, G. R., and Hannan, M. T. (1983). The Liability of Newness: Age Dependence in Organizational Death Rates. American Sociological Review, 48(5):692.

Geurts, K. and Van Biesebroeck, J. (2016). Firm creation and post-entry dynamics of de novo entrants. International Journal of Industrial Organization, 49:59-104.

Gibbons, R. and Katz, L. F. (1991). Layoffs and Lemons. Journal of Labor Economics, 9(4):351380.

Gimeno, J., Folta, T. B., Cooper, A. C., and Woo, C. Y. (1997). Survival of the Fittest? Entrepreneurial Human Capital and the Persistence of Underperforming Firms. Administrative Science Quarterly, 42(4):750.

Gottlieb, J. D., Townsend, R. R., and Xu, T. (2016). Does Career Risk Deter Potential Entrepreneurs? Ssrn.

Greenwald, B. C. (1986). Adverse Selection in the Labour Market. The Review of Economic Studies, 53(3):325.

Groysberg, B., Nanda, A., and Prats, M. J. (2007). Does Individual Performance Affect Entrepreneurial Mobility? Empirical Evidence from the Financial Analysis Market. Technical report, National Bureau of Economic Research, Cambridge, MA.

Guzman, J. and Stern, S. (2017). Nowcasting and Placecasting Entrepreneurial Quality and Performance. Technical Report December, National Bureau of Economic Research, Cambridge, MA.

Hall, R. E. and Krueger, A. B. (2012). Evidence on the incidence of wage posting, wage bargaining, and on-the-job search. American Economic Journal: Macroeconomics, 4(4):56-67. 
Hamilton, B. H. (2000). Does Entrepreneurship Pay? An Empirical Analysis of the Returns to Self-Employment. Journal of Political Economy, 108(3):604-631.

Hendricks, W. E., Debrock, L., and Koenker, R. (2001). Uncertainty, Hiring and Subsequent Performance: The NFL Draft. Ssrn, 21(4):857-886.

Hyytinen, A. and Rouvinen, P. (2008). The labour market consequences of self-employment spells: European evidence. Labour Economics, 15(2):246-271.

Iacus, S. M., King, G., and Porro, G. (2012). Causal Inference without Balance Checking: Coarsened Exact Matching. Political Analysis, 20(1):1-24.

Ioannides, Y. M. and Loury, L. D. (2004). Job Information Networks, Neighborhood Effects, and Inequality. Journal of Economic Literature, 42(4):1056-1093.

Jackson, C. K. (2013). Match quality, worker productivity, and worker mobility: Direct evidence from teachers. Review of Economics and Statistics, 95(4):1096-1116.

Jacobson, L. S., Lalonde, R. J., and Sullivan, D. G. (1993). American Economic Association Earnings Losses of Displaced Workers Earnings Losses of Displaced Workers. The American Economic Review, 83(4):685-709.

Jovanovic, B. (1979). Job Matching and the Theory of Turnover. Journal of Political Economy, 87(5):972-990.

Kaiser, U. and Malchow-Møller, N. (2011). Is self-employment really a bad experience?. The effects of previous self-employment on subsequent wage-employment wages. Journal of Business Venturing, 26(5):572-588.

Kerr, W. R., Nanda, R., and Rhodes-Kropf, M. (2014). Entrepreneurship as Experimentation. Journal of Economic Perspectives, 28(3):25-48.

King, G., Stuart, E. A., Imai, K., and Ho, D. E. (2007). Matching as Nonparametric Preprocessing for Reducing Model Dependence in Parametric Causal Inference. Political Analysis, 15:199-236.

Koellinger, P. D., Mell, J. N., Pohl, I., Roessler, C., and Treffers, T. (2015). Self-employed but looking: A labour market experiment. Economica, 82(325):137-161.

Kuhnen, C. M. and Oyer, P. (2016). Exploration for Human Capital: Evidence from the MBA Labor Market. Journal of Labor Economics, 34(S2):S255-S286.

Landier, A. (2005). Entrepreneurship and the Stigma of Failure. Ssrn.

Lazear, E. (1995). Hiring Risky Workers. In Internal Labour Markets, Incentives and Employment, pages 143-158. Palgrave Macmillan UK, London.

Lazear, E. P. (1981). Agency, Earnings Profiles, Productivity, and Hours Restrictions. The American Economic Review, 71(4):606-620.

Lazear, E. P. (2005). Entrepreneurship. Journal of Labor Economics, 23(4):649-680. 
Lazear, E. P. (2012). Leadership: A personnel economics approach. Labour Economics, 19(1):92101.

Lazear, E. P., Shaw, K. L., and Stanton, C. T. (2018). Who Gets Hired? The Importance of Competition among Applicants. Journal of Labor Economics, 36(S1):S133-S181.

Levine, R. and Rubinstein, Y. (2016). Smart and Illicit: Who Becomes an Entrepreneur and Do They Earn More? The Quarterly Journal of Economics, 132(2):963-1018.

Luzzi, A. and Sasson, A. (2016). Individual Entrepreneurial Exit and Earnings in Subsequent Paid Employment. Entrepreneurship: Theory and Practice, 40(2):401-420.

Manso, G. (2016). Experimentation and the Returns to Entrepreneurship. Review of Financial Studies, 29(9):2319-2340.

Mincer, J. and Ofek, H. (1982). Interrupted Work Careers: Depreciation and Restoration of Human Capital. The Journal of Human Resources, 17(1):3.

Moallemi, B., Ramakrishnan, R., and Shyu, R. (2017). The Labor Market Signaling Value of Promotions. SSRN Electronic Journal.

Nanda, R. and Sørensen, J. B. (2010). Workplace Peers and Entrepreneurship. Management Science, 56(7):1116-1126.

Neal, D. (1995). Industry-Specific Human Capital: Evidence from Displaced Workers. Journal of Labor Economics, 13(4):653-677.

Oi, W. Y. and Idson, T. L. (1999). Chapter 33 Firm size and wages. In Handbook of Labor Economics, volume 3 PART, pages 2165-2214. Elsevier.

Oyer, P. and Schaefer, S. (2011). Personnel Economics: Hiring and Incentives. In Ashenfelter, O. and Card, D., editors, Handbook of Labor Economics, volume 4, chapter 20, pages 1769-1823. North Holland, Amsterdam.

Özcan, S. and Reichstein, T. (2009). Transition to Entrepreneurship from the Public Sector: Predispositional and Contextual Effects. Management Science, 55(4):604-618.

Pallais, A. (2014). Inefficient hiring in entry-level labor markets. American Economic Review, 104(11):3565-3599.

Parker, S. C. (2009). The economics of entrepreneurship. Cambridge University Press, Cambridge.

Pfann, G. A. (2006). Downsizing and Heterogeneous Firing Costs. Review of Economics and Statistics, 88(1):158-170.

Polachek, S. (1981). Occupational Self-selection: A Human Capital Approach to Sex Differences in Occupational Structure. The Review of Economics and Statistics, 63(1):60-69.

Polkovnichenko, V. (2003). Human capital and the private equity premium. Review of Economic Dynamics, 6(4):831-845. 
Ries, E. (2011). The lean startup : how today's entrepreneurs use continuous innovation to create radically successful businesses. Crown Business.

Rosen, S. (1986). The theory of equalizing differences. In Handbook of Labor Economics, volume 1, pages 641-692. Elsevier.

Rosenbaum, P. R. and Rubin, D. B. (1983). The central role of the propensity score in observational studies for causal effects. Biometrika, 70(1):41-55.

Rosenbaum, P. R. and Rubin, D. B. (1985). Constructing a control group using multivariate matched sampling methods that incorporate the propensity score. American Statistician, 39(1):33-38.

Schönberg, U. (2007). Testing for Asymmetric Employer Learning. Journal of Labor Economics, 25(4):651-691.

Serfling, M. (2016). Firing Costs and Capital Structure Decisions. The Journal of Finance, 71(5):2239-2286.

Singh, S., Corner, P. D., and Pavlovich, K. (2015). Failed, not finished: A narrative approach to understanding venture failure stigmatization. Journal of Business Venturing, 30(1):150-166.

Sørensen, J. B. (2007). Bureaucracy and Entrepreneurship: Workplace Effects on Entrepreneurial Entry. Administrative Science Quarterly, 52(3):387-412.

Spence, M. (1973). Job Market Signaling. The Quarterly Journal of Economics, 87(3):355.

Stinchcombe, A. L. (1965). Social structure and organizations. In March, J., editor, Handbook of Organizations, pages 229-259.

Stuart, E. A. (2010). Matching Methods for Causal Inference: A Review and a Look Forward. Statistical Science, 25(1):1-21.

Stuart, T. E., Hoang, H., and Hybels, R. C. (1999). Interorganizational Endorsements and the Performance of Entrepreneurial Ventures. Administrative Science Quarterly, 44(2):315.

Tate, G. and Yang, L. (2015). The Bright Side of Corporate Diversification: Evidence from Internal Labor Markets. Review of Financial Studies, 28(8):2203-2249.

Waldman, M. (1984). Job Assignments, Signalling, and Efficiency. The RAND Journal of Economics, 15(2):255.

Wasserman, N. (2012). The founder's dilemmas : anticipating and avoiding the pitfalls that can sink a startup. Princeton University Press.

Westhead, P. and Wright, M. (1998). Novice, portfolio, and serial founders: Are they different? Journal of Business Venturing, 13(3):173-204.

Williams, D. R. (2000). Consequences of self-employment for women and men in the United States. Labour Economics, 7(5):665-687.

Zimmer, H. (2012). Labour market mismatches. Economic Review, National Bank of Belgium, ii:55-68. 


\section{Figures}

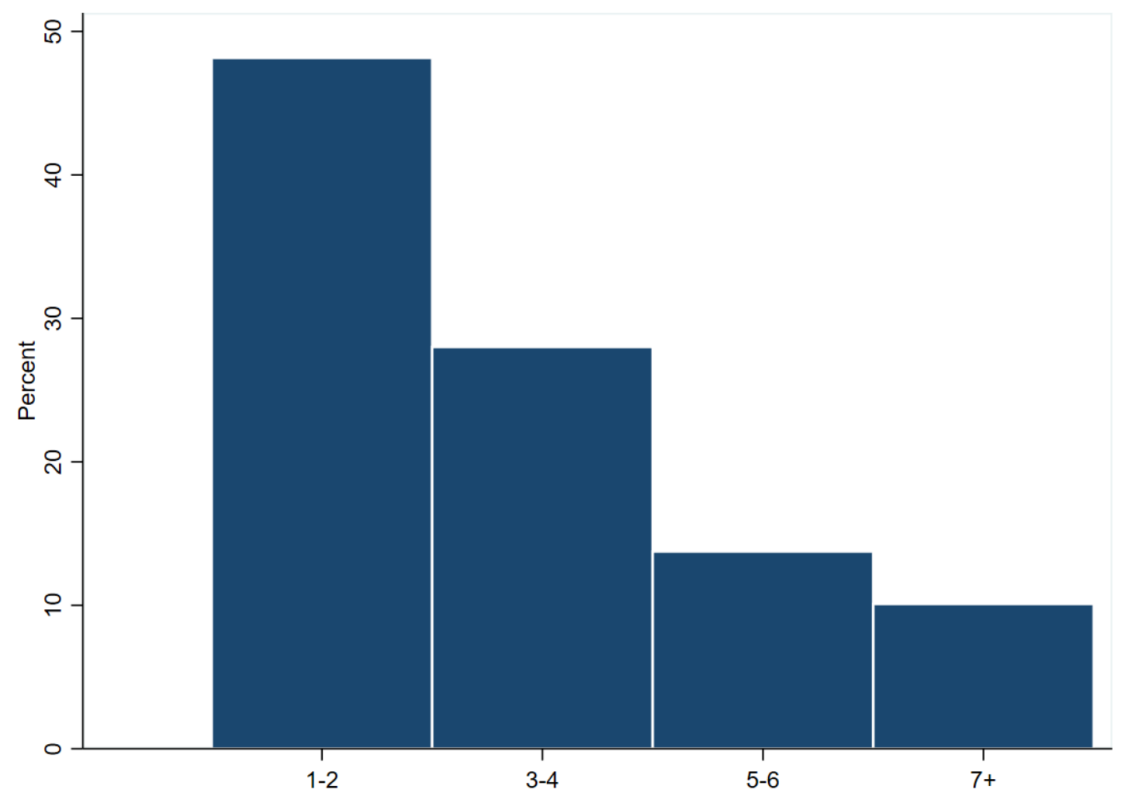

Figure 1: Duration of entrepreneurial spells (in years)

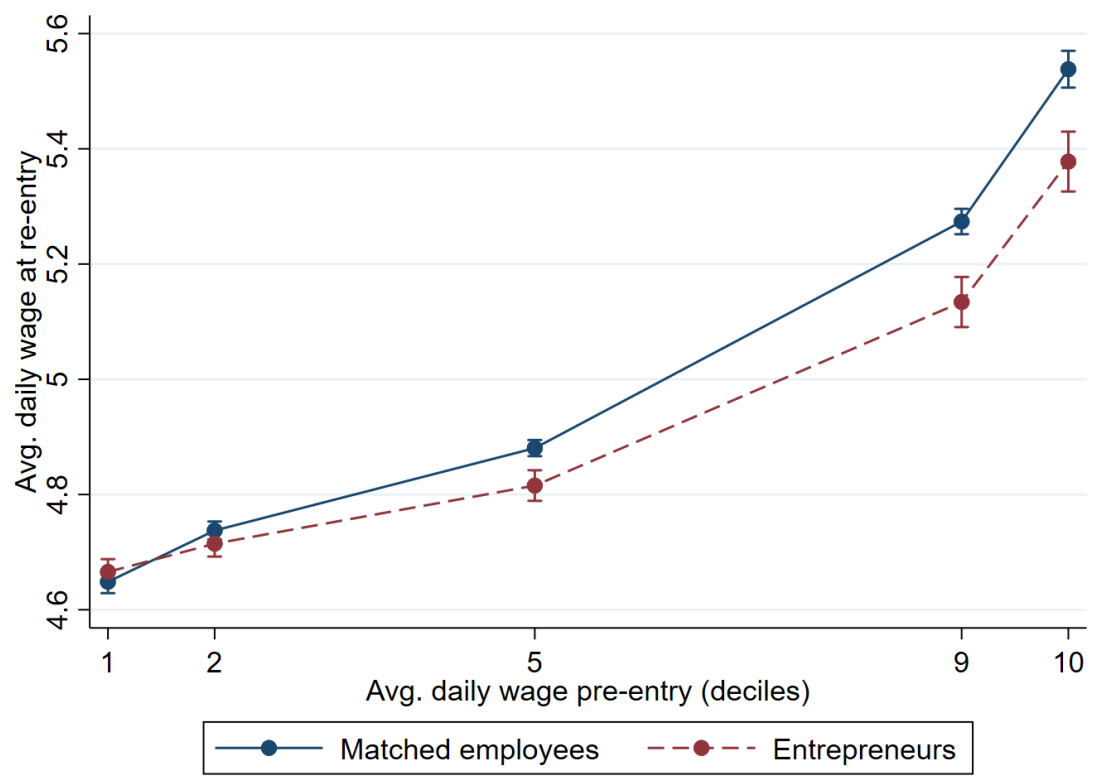

Figure 2: Plot of predictive margins of $\ln \left(\right.$ wage $\left._{1}\right)$ at different levels of the avg. daily wage at the pre-entry stage: entrepreneurs vs. matched employees 


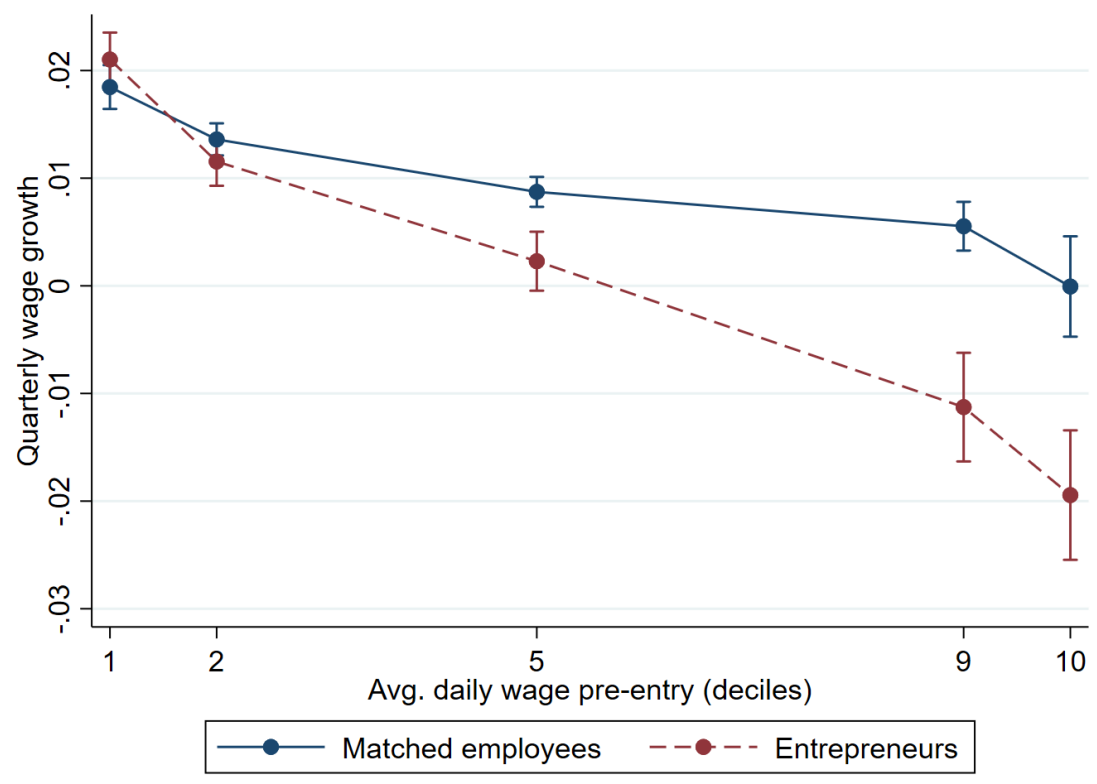

Figure 3: Plot of predictive margins of $\Delta$ wage at different levels of the avg. daily wage at the preentry stage: entrepreneurs vs. matched employees

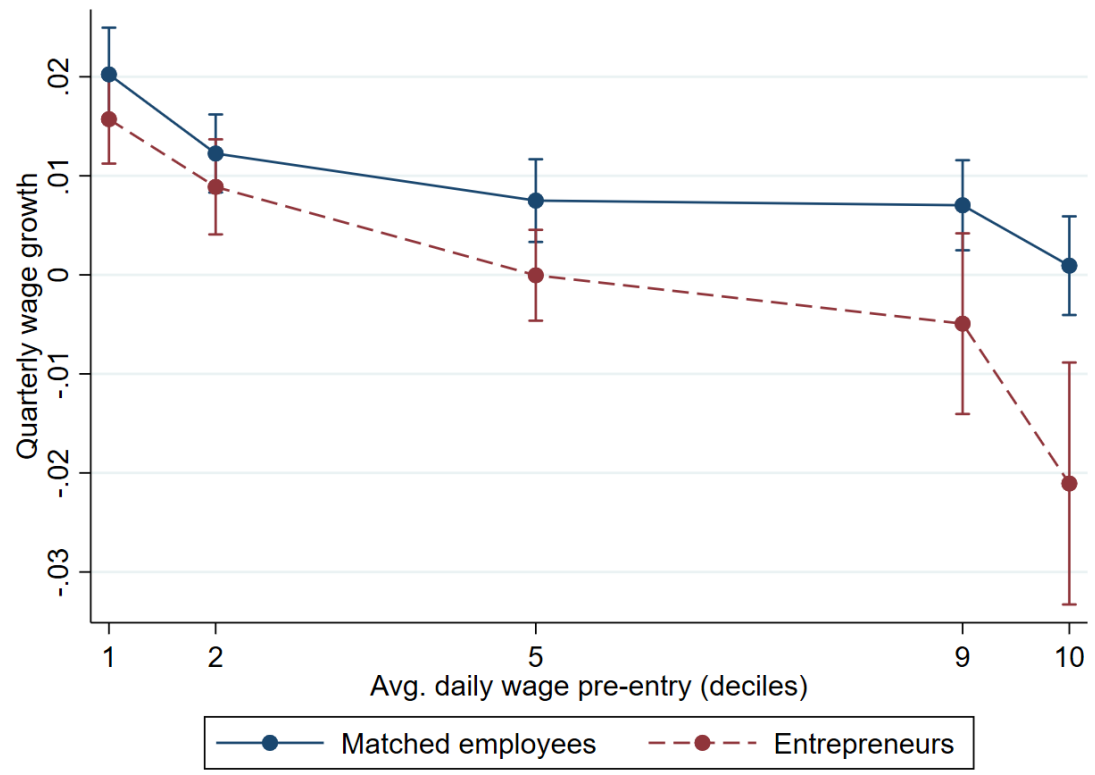

Figure 4: Plot of predictive margins of $\Delta$ wage at different levels of the avg. daily wage at the preentry stage: entrepreneurs and matched employees who change jobs at the time entrepreneurs reenter wage work 


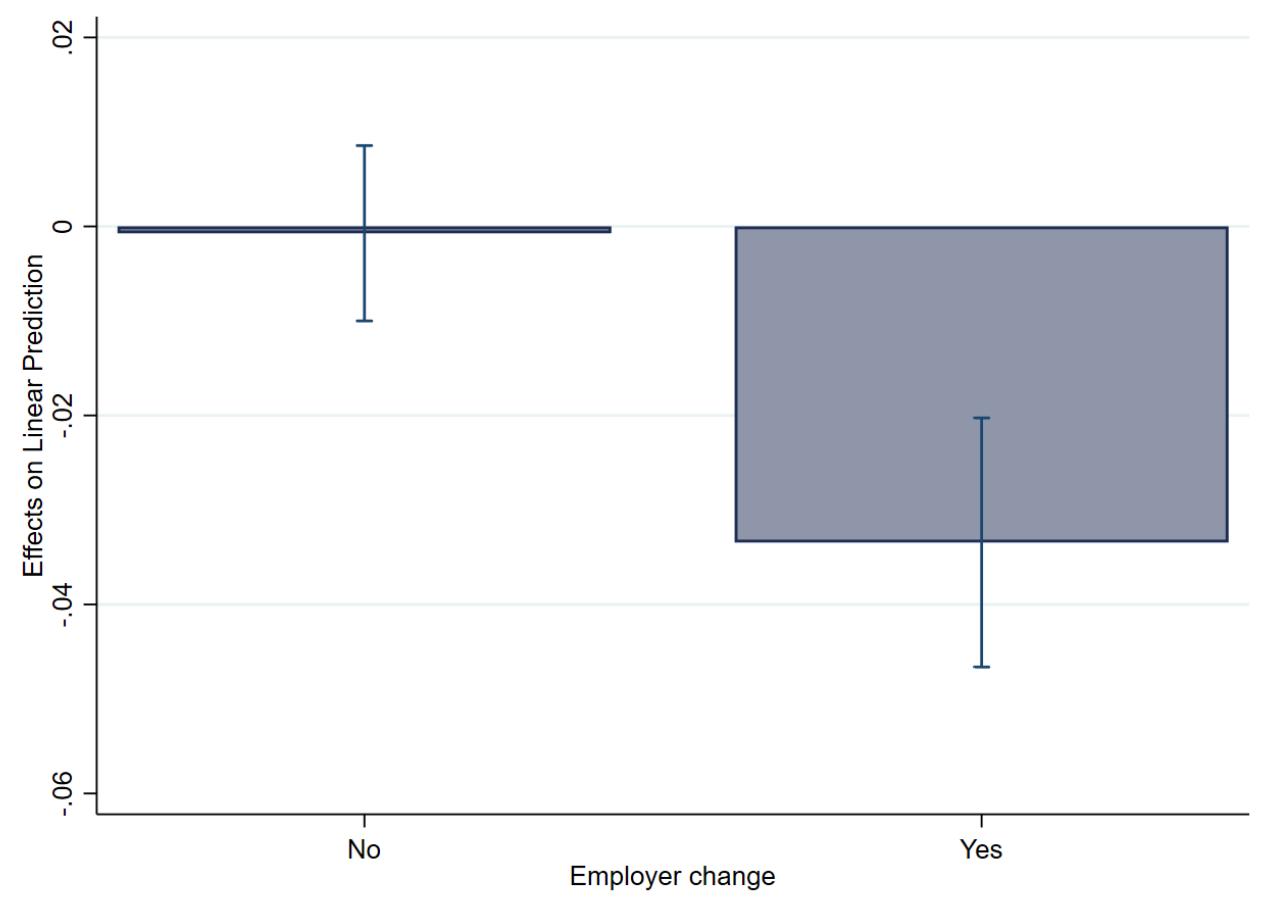

Figure 5: Marginal effects of entrepreneur at the top $10 \%$ of the pre-entry wage distribution and for spells $<$ five years by whether they work for the same employer in the pre-entry and re-entry quarters 


\section{Tables}

Table 1: Sampling and restrictions

\begin{tabular}{lccccc} 
& \multicolumn{3}{c}{ Restriction criteria } & & \\
\cline { 2 - 6 } & Full sample & Matching & Non-necessity & Return & Full-time job \\
\hline Entrepreneurs & 87,614 & 32,473 & 23,792 & 5,565 & 2,735 \\
Individuals & 124.88 & 109.19 & 109.53 & 105.28 & 108.95 \\
Daily wage Q1 2004 & & & & & \\
Wage employees & 835,969 & 32,473 & 23,792 & 5,565 & 2,735 \\
Individuals & 118.51 & 109.19 & 109.53 & 105.28 & 108.95 \\
Daily wage Q1 2004 & & & & & \\
\hline
\end{tabular}


Table 2: Summary statistics at the pre-entry and re-entry quarters

\begin{tabular}{|c|c|c|c|c|c|c|c|c|}
\hline & \multicolumn{4}{|c|}{ Pre-entry } & \multicolumn{4}{|c|}{ Re-entry } \\
\hline & \multicolumn{2}{|c|}{ Entrepreneurs } & \multicolumn{2}{|c|}{ Matched employees } & \multicolumn{2}{|c|}{ Entrepreneurs } & \multicolumn{2}{|c|}{ Matched employees } \\
\hline & mean & $\mathrm{sd}$ & mean & $\mathrm{sd}$ & mean & $\mathrm{sd}$ & mean & $\mathrm{sd}$ \\
\hline Avg. daily wage & 127.631 & 52.34 & 127.726 & 46.72 & 136.625 & 59.60 & $147.086^{* * *}$ & 54.46 \\
\hline$\Delta$ wage & & & & & 0.003 & 0.03 & $0.010 * * *$ & 0.02 \\
\hline Spell length & & & & & 14.324 & 8.72 & 14.324 & 8.72 \\
\hline Employer change & & & & & 0.817 & 0.39 & $0.230 * * *$ & 0.42 \\
\hline Employer tenure & 16.277 & 11.81 & $20.423 * * *$ & 11.92 & 5.463 & 10.23 & $29.624 * * *$ & 16.49 \\
\hline Nr. of employers & 2.793 & 2.26 & $2.165 * * *$ & 1.72 & 3.610 & 2.34 & $2.479 * * *$ & 1.97 \\
\hline \multicolumn{9}{|l|}{ Occupation } \\
\hline Blue-collar & 0.505 & 0.50 & 0.494 & 0.50 & 0.483 & 0.50 & 0.472 & 0.50 \\
\hline White-collar & 0.455 & 0.50 & 0.450 & 0.50 & 0.474 & 0.50 & 0.462 & 0.50 \\
\hline Govt. official & 0.040 & 0.20 & $0.056^{* *}$ & 0.23 & 0.042 & 0.20 & $0.065 * * *$ & 0.25 \\
\hline \multicolumn{9}{|l|}{ Employer size } \\
\hline$<5$ & 0.136 & 0.34 & $0.094 * * *$ & 0.29 & 0.183 & 0.39 & $0.077 * * *$ & 0.27 \\
\hline $5-9$ & 0.117 & 0.32 & $0.093 * *$ & 0.29 & 0.115 & 0.32 & $0.083 * * *$ & 0.28 \\
\hline $10-19$ & 0.119 & 0.32 & 0.107 & 0.31 & 0.114 & 0.32 & 0.105 & 0.31 \\
\hline $20-49$ & 0.180 & 0.38 & 0.171 & 0.38 & 0.162 & 0.37 & 0.170 & 0.38 \\
\hline $50-99$ & 0.083 & 0.28 & 0.095 & 0.29 & 0.068 & 0.25 & $0.096^{* * *}$ & 0.29 \\
\hline 100-199 & 0.063 & 0.24 & $0.084 * *$ & 0.28 & 0.061 & 0.24 & $0.092 * * *$ & 0.29 \\
\hline $200-499$ & 0.084 & 0.28 & $0.114 * * *$ & 0.32 & 0.085 & 0.28 & $0.112 * * *$ & 0.32 \\
\hline $500-999$ & 0.050 & 0.22 & 0.057 & 0.23 & 0.039 & 0.19 & $0.060 * * *$ & 0.24 \\
\hline$\geqslant 1000$ & 0.167 & 0.37 & 0.186 & 0.39 & 0.172 & 0.38 & $0.205^{* *}$ & 0.40 \\
\hline \multicolumn{9}{|l|}{ Employer sector } \\
\hline Private & 0.927 & 0.26 & 0.914 & 0.28 & 0.888 & 0.31 & $0.907 *$ & 0.29 \\
\hline \multicolumn{9}{|l|}{ Employer Industry } \\
\hline Manufacturing & 0.205 & 0.40 & $0.240^{* *}$ & 0.43 & 0.144 & 0.35 & $0.235^{* * *}$ & 0.42 \\
\hline Electricity, gas, water & 0.001 & 0.03 & 0.003 & 0.05 & 0.004 & 0.06 & 0.005 & 0.07 \\
\hline Construction & 0.241 & 0.43 & 0.224 & 0.42 & 0.236 & 0.42 & $0.211^{*}$ & 0.41 \\
\hline Wholesale and retail trade & 0.213 & 0.41 & 0.204 & 0.40 & 0.197 & 0.40 & 0.203 & 0.40 \\
\hline Hotels and restaurants & 0.012 & 0.11 & 0.010 & 0.10 & 0.018 & 0.13 & $0.010^{*}$ & 0.10 \\
\hline Transport, storage, communication & 0.088 & 0.28 & 0.088 & 0.28 & 0.099 & 0.30 & 0.092 & 0.29 \\
\hline Financial institutions & 0.032 & 0.18 & 0.033 & 0.18 & 0.034 & 0.18 & 0.034 & 0.18 \\
\hline Real estate and professional services & 0.130 & 0.34 & 0.119 & 0.32 & 0.136 & 0.34 & 0.119 & 0.32 \\
\hline Public administration, defence & 0.032 & 0.18 & 0.039 & 0.19 & 0.056 & 0.23 & 0.046 & 0.21 \\
\hline Education & 0.019 & 0.14 & 0.018 & 0.13 & 0.028 & 0.16 & $0.018^{*}$ & 0.13 \\
\hline Healthcare and support services & 0.013 & 0.11 & 0.012 & 0.11 & 0.025 & 0.16 & $0.014^{* *}$ & 0.12 \\
\hline Social and cultural services & 0.011 & 0.11 & 0.009 & 0.10 & 0.020 & 0.14 & $0.012 *$ & 0.11 \\
\hline Observations & \multicolumn{2}{|c|}{2,735} & \multicolumn{2}{|c|}{2,73} & \multicolumn{2}{|c|}{2,735} & \multicolumn{2}{|l|}{2,7} \\
\hline
\end{tabular}

Summary statistics of entrepreneurs and matched employees at the quarters of pre-entry and re-entry. Stars indicate significant differences between the two groups.

$* \mathrm{p}<0.05 * * \mathrm{p}<0.01 * * * \mathrm{p}<0.001$ 
Table 3: Quantile regressions on the average daily wage at the quarter of pre-entry, and OLS regressions on the average daily wage at the quarter of re-entry, and quarterly wage growth.

\begin{tabular}{|c|c|c|c|c|c|c|c|c|c|}
\hline & \multicolumn{5}{|c|}{ Quantile regression on $\ln \left(\right.$ wage $\left._{0}\right)$, percentile } & \multicolumn{4}{|c|}{ OLS } \\
\hline & $\begin{array}{l}\text { 10th } \\
(1)\end{array}$ & $\begin{array}{l}25 \text { th } \\
(2)\end{array}$ & $\begin{array}{l}50 \text { th } \\
(3)\end{array}$ & $\begin{array}{l}75 \text { th } \\
(4)\end{array}$ & $\begin{array}{l}\text { 90th } \\
(5)\end{array}$ & $\begin{array}{c}\ln \left(\text { wage }_{1}\right) \\
(6)\end{array}$ & $\begin{array}{c}\ln \left(\text { wage }_{1}\right) \\
\text { (7) }\end{array}$ & $\begin{array}{c}\Delta \ln (\text { wage }) \\
(8)\end{array}$ & $\begin{array}{c}\Delta \ln (\text { wage }) \\
(9)\end{array}$ \\
\hline Entrepreneur & $\begin{array}{l}-0.009 \\
(0.007)\end{array}$ & $\begin{array}{l}-0.001 \\
(0.006)\end{array}$ & $\begin{array}{c}0.002 \\
(0.006)\end{array}$ & $\begin{array}{c}0.009 \\
(0.006)\end{array}$ & $\begin{array}{c}0.008 \\
(0.008)\end{array}$ & $\begin{array}{c}-0.057 * * * \\
(0.006)\end{array}$ & $\begin{array}{c}0.017 \\
(0.014)\end{array}$ & $\begin{array}{c}-0.006^{* * *} \\
(0.001)\end{array}$ & $\begin{array}{c}0.003 \\
(0.002)\end{array}$ \\
\hline$W_{0}$, decile $=2$ & & & & & & $\begin{array}{c}0.064 * * * \\
(0.010)\end{array}$ & $\begin{array}{c}0.089 * * * \\
(0.011)\end{array}$ & $\begin{array}{c}-0.008 * * * \\
(0.001)\end{array}$ & $\begin{array}{c}-0.005^{* * * *} \\
(0.001)\end{array}$ \\
\hline$W_{0}$, decile $=5$ & & & & & & $\begin{array}{c}0.185^{* * * *} \\
(0.011)\end{array}$ & $\begin{array}{c}0.232 * * * \\
(0.012)\end{array}$ & $\begin{array}{c}-0.015^{* * *} \\
(0.001)\end{array}$ & $\begin{array}{c}-0.010^{* * *} \\
(0.001)\end{array}$ \\
\hline$W_{0}$, decile $=9$ & & & & & & $\begin{array}{c}0.540 * * * \\
(0.016)\end{array}$ & $\begin{array}{c}0.625^{* * * *} \\
(0.016)\end{array}$ & $\begin{array}{c}-0.023 * * * \\
(0.002)\end{array}$ & $\begin{array}{c}-0.013^{* * *} \\
(0.002)\end{array}$ \\
\hline$W_{0}$, decile $=10$ & & & & & & $\begin{array}{c}0.790 * * * \\
(0.020)\end{array}$ & $\begin{array}{c}0.890 * * * \\
(0.020)\end{array}$ & $\begin{array}{c}-0.031 * * * \\
(0.002)\end{array}$ & $\begin{array}{c}-0.019^{* * *} \\
(0.003)\end{array}$ \\
\hline Entrepreneur $\# W_{0}$, decile $=2$ & & & & & & & $\begin{array}{l}-0.040^{*} \\
(0.019)\end{array}$ & & $\begin{array}{l}-0.005^{*} \\
(0.002)\end{array}$ \\
\hline Entrepreneur $\# W_{0}$, decile $=5$ & & & & & & & $\begin{array}{c}-0.082 * * * \\
(0.020)\end{array}$ & & $\begin{array}{c}-0.009^{* * *} \\
(0.002)\end{array}$ \\
\hline Entrepreneur $\# W_{0}$, decile $=9$ & & & & & & & $\begin{array}{c}-0.157 * * * \\
(0.028)\end{array}$ & & $\begin{array}{c}-0.019^{* * *} \\
(0.003)\end{array}$ \\
\hline Entrepreneur $\# W_{0}$, decile $=10$ & & & & & & & $\begin{array}{c}-0.178 * * * \\
(0.032)\end{array}$ & & $\begin{array}{c}-0.022 * * * \\
(0.004)\end{array}$ \\
\hline Constant & $\begin{array}{c}5.489 * * * \\
(0.108)\end{array}$ & $\begin{array}{c}5.382 * * * \\
(0.099)\end{array}$ & $\begin{array}{c}5.066^{* * * *} \\
(0.108)\end{array}$ & $\begin{array}{c}4.910 * * * \\
(0.106)\end{array}$ & $\begin{array}{c}5.603 * * * \\
(0.099)\end{array}$ & $\begin{array}{c}4.454 * * * \\
(0.114)\end{array}$ & $\begin{array}{c}4.397 * * * \\
(0.113)\end{array}$ & $\begin{array}{c}0.008 \\
(0.017)\end{array}$ & $\begin{array}{c}0.001 \\
(0.017)\end{array}$ \\
\hline Observations & 5,470 & 5,470 & 5,470 & 5,470 & 5,470 & 5,470 & 5,470 & 5,470 & 5,470 \\
\hline R-squared & 0.331 & 0.419 & 0.464 & 0.458 & 0.422 & 0.645 & 0.651 & 0.153 & 0.171 \\
\hline
\end{tabular}

Additional control variables (not displayed): age, gender, household position, region, occupation, employer sector, employer industry, employer size, employer tenure, nr. of jobs held, employer change, spell length, quarter fixed effects. Robust standard errors in parentheses. ${ }^{*} \mathrm{p}<0.05$ $* * \mathrm{p}<0.01 * * * \mathrm{p}<0.001$. 
Table 4: Quarterly wage growth over different spell durations: marginal effects of entrepreneur at different deciles of avg. daily wage pre-entry.

\begin{tabular}{l|ccccc} 
& \multicolumn{5}{|c}{ Spell duration (years) } \\
Pre-entry wage (decile) & All & $1-2$ & $3-4$ & $5-6$ & $7+$ \\
\hline \hline 1 st & $0.003^{*}$ & 0.006 & 0.003 & 0.002 & -0.001 \\
& $(0.002)$ & $(0.003)$ & $(0.002)$ & $(0.002)$ & $(0.002)$ \\
\multirow{4}{*}{ nd } & -0.001 & -0.004 & 0.001 & 0.002 & -0.001 \\
& $(0.001)$ & $(0.003)$ & $(0.002)$ & $(0.002)$ & $(0.002)$ \\
th & $-0.006^{* * *}$ & $-0.010^{* * *}$ & -0.002 & -0.003 & -0.002 \\
& $(0.002)$ & $(0.003)$ & $(0.002)$ & $(0.002)$ & $(0.002)$ \\
9th & $-0.017^{* * *}$ & $-0.022^{* * *}$ & $-0.013 * *$ & -0.005 & 0.001 \\
10 th & $(0.003)$ & $(0.004)$ & $(0.004)$ & $(0.003)$ & $(0.005)$ \\
& $-0.018^{* * *}$ & $-0.027^{* * *}$ & $-0.010^{* *}$ & -0.008 & -0.004 \\
& $(0.004)$ & $(0.006)$ & $(0.004)$ & $(0.004)$ & $(0.003)$ \\
Observations & & & & & \\
\hline
\end{tabular}

Standard errors in parentheses. ${ }^{*} \mathrm{p}<0.05 * * \mathrm{p}<0.01 * * * \mathrm{p}<0.001$ 
Table 5: Quarterly wage growth by employer size: marginal effects of entrepreneur at different deciles of avg. daily wage pre-entry.

\begin{tabular}{l|cc}
\multirow{2}{*}{ Pre-entry wage (decile) } & \multicolumn{2}{|c}{ Employer size } \\
Small & Large \\
\hline 1st & $0.009 * *$ & -0.001 \\
& $(0.002)$ & $(0.003)$ \\
2nd & -0.003 & -0.003 \\
& $(0.002)$ & $(0.002)$ \\
5 th & $-0.007 *$ & $-0.009 * *$ \\
& $(0.003)$ & $(0.003)$ \\
9 th & $-0.032 * * *$ & $-0.017 * * *$ \\
& $(0.008)$ & $(0.004)$ \\
10th & $-0.047 * * *$ & $-0.014 * * *$ \\
& $(0.009)$ & $(0.005)$ \\
& & \\
Observations & 4,166 & 4,166 \\
\hline
\end{tabular}

Only spells shorter than five years. Standard errors in parentheses. $* \mathrm{p}<0.05 * * \mathrm{p}<0.01$

$* * * \mathrm{p}<0.001$ 
Table 6: OLS regressions on the probability of joining a small employer at the quarter of re-entry in wage employment

\begin{tabular}{|c|c|c|}
\hline VARIABLES & $\begin{array}{c}(1) \\
\text { Raw measure }\end{array}$ & $\begin{array}{c}(2) \\
\text { Log measure }\end{array}$ \\
\hline mean entrepreneurial earnings & $\begin{array}{l}-0.000 \\
(0.000)\end{array}$ & \\
\hline $\ln ($ mean entrepreneurial earnings) & & $\begin{array}{c}0.013 \\
(0.033)\end{array}$ \\
\hline$W_{0}$, decile $=2$ & $\begin{array}{l}-0.110 \\
(0.131)\end{array}$ & $\begin{array}{l}-0.121 \\
(0.145)\end{array}$ \\
\hline$W_{0}$, decile $=5$ & $\begin{array}{l}-0.020 \\
(0.148)\end{array}$ & $\begin{array}{l}-0.045 \\
(0.164)\end{array}$ \\
\hline$W_{0}$, decile $=9$ & $\begin{array}{l}-0.360 * \\
(0.168)\end{array}$ & $\begin{array}{l}-0.453 * \\
(0.180)\end{array}$ \\
\hline$W_{0}$, decile $=10$ & $\begin{array}{l}-0.332 \\
(0.177)\end{array}$ & $\begin{array}{l}-0.410 * \\
(0.190)\end{array}$ \\
\hline Constant & $\begin{array}{l}-0.397 \\
(0.877)\end{array}$ & $\begin{array}{l}-0.553 \\
(0.929)\end{array}$ \\
\hline $\begin{array}{l}\text { Observations } \\
\text { Pseudo } R^{2}\end{array}$ & $\begin{array}{l}1,630 \\
0.149\end{array}$ & $\begin{array}{l}1,339 \\
0.150\end{array}$ \\
\hline
\end{tabular}

Additional control variables (not displayed): age, gender, household position, region, industry, pre-entry employer size, spell length, quarter fixed effects. Standard errors in parentheses. $* \mathrm{p}<0.05 * * \mathrm{p}<0.01 * * * \mathrm{p}<0.001$. 


\section{Appendix}

Table A1: Balance of full and matched samples

\begin{tabular}{|c|c|c|c|c|c|c|}
\hline & \multicolumn{3}{|c|}{ Full sample } & \multicolumn{3}{|c|}{ Matched sample } \\
\hline & Entrepreneurs & Wage employees & Std. \% bias & Entrepreneurs & Wage employees & Std. \% bias \\
\hline \multicolumn{7}{|c|}{ 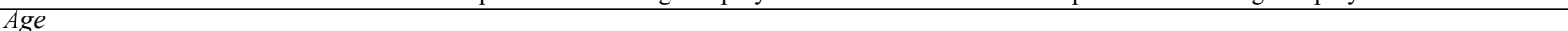 } \\
\hline $22-24$ & 0.0445 & 0.1030 & -22.5 & 0.0863 & 0.0863 & 0.0 \\
\hline $25-29$ & 0.2931 & 0.1525 & 34.3 & 0.3208 & 0.3208 & 0.0 \\
\hline $30-34$ & 0.2567 & 0.1857 & 17.2 & 0.2668 & 0.2668 & 0.0 \\
\hline $35-39$ & 0.1759 & 0.2125 & -9.2 & 0.1734 & 0.1734 & 0.0 \\
\hline $40-44$ & 0.1115 & 0.2319 & -32.4 & 0.1034 & 0.1034 & 0.0 \\
\hline $45-49$ & 0.0597 & 0.1729 & -35.9 & 0.0492 & 0.0492 & 0.0 \\
\hline Female & 0.2501 & 0.3329 & -18.3 & 0.2072 & 0.2072 & 0.0 \\
\hline \multicolumn{7}{|l|}{ Region } \\
\hline Flanders & 0.6654 & 0.6516 & 2.9 & 0.7861 & 0.7861 & 0.0 \\
\hline Wallonia & 0.2416 & 0.2850 & -9.9 & 0.1943 & 0.1943 & 0.0 \\
\hline Brussels & 0.0929 & 0.0633 & 11.0 & 0.0195 & 0.0195 & 0.0 \\
\hline \multicolumn{7}{|l|}{ Household position } \\
\hline Living with parents & 0.1614 & 0.1231 & 11.0 & 0.1911 & 0.1928 & 0.4 \\
\hline Single & 0.1445 & 0.1184 & 7.7 & 0.1216 & 0.1198 & 0.6 \\
\hline Cohabiting - 0 children & 0.1991 & 0.1647 & 8.9 & 0.2014 & 0.2062 & -1.2 \\
\hline Cohabiting - 1 child & 0.1715 & .1923 & -5.4 & 0.1798 & 0.1792 & 0.2 \\
\hline Cohabiting - 2 children & 0.1933 & 0.2480 & -13.2 & 0.1991 & 0.1983 & 0.2 \\
\hline Cohabiting - $3>$ children & 0.0756 & 0.0929 & -6.2 & 0.0635 & 0.06402 & -0.2 \\
\hline Head 1 parent family -1 child & 0.0134 & 0.0201 & -5.2 & 0.0085 & 0.0087 & -0.2 \\
\hline Head 1 parent family $-2>$ children & 0.0107 & 0.0174 & -5.7 & 0.0067 & 0.0068 & -0.1 \\
\hline Other & 0.0301 & 0.0227 & 4.6 & 0.0263 & 0.0257 & 0.4 \\
\hline \multicolumn{7}{|l|}{ Occupation } \\
\hline Blue-collar & 0.3492 & 0.3399 & 2.0 & 0.4714 & 0.4752 & 0.8 \\
\hline White-collar/Govt. official & 0.6508 & 0.6600 & -2.0 & 0.5248 & 0.5285 & -0.8 \\
\hline \multirow{2}{*}{\multicolumn{7}{|c|}{ Employer Industry }} \\
\hline & & & & & & \\
\hline Manufacturing & 0.1812 & 0.2372 & -13.8 & 0.2529 & 0.2529 & 0.0 \\
\hline Electricity, gas, water & 0.0023 & 0.0088 & -8.6 & 0.0004 & 0.0004 & 0.0 \\
\hline Construction & 0.1445 & 0.0643 & 26.5 & 0.1906 & 0.1906 & 0.0 \\
\hline Wholesale and retail trade & 0.2065 & 0.1313 & 20.2 & 0.2068 & 0.2068 & 0.0 \\
\hline Hotels and restaurants & 0.0338 & 0.0105 & 12.9 & 0.0099 & 0.0099 & 0.0 \\
\hline Transport, storage, communication & 0.0699 & 0.0989 & -10.4 & 0.0638 & 0.0638 & 0.0 \\
\hline Financial institutions & 0.0460 & 0.0541 & -3.7 & 0.0329 & 0.0329 & 0.0 \\
\hline Real estate and professional services & 0.1735 & 0.0892 & 22.3 & 0.1312 & 0.1312 & 0.0 \\
\hline Public administration, defence & 0.0229 & 0.0998 & -32.5 & 0.0285 & 0.0285 & 0.0 \\
\hline Education & 0.0237 & 0.0939 & -30.2 & 0.0257 & 0.0257 & 0.0 \\
\hline Healthcare and support services & 0.0543 & 0.0849 & -12.1 & 0.0455 & 0.0455 & 0.0 \\
\hline Social and cultural services & 0.0392 & 0.0254 & 7.8 & 0.0112 & 0.0112 & 0.0 \\
\hline Households as employers & 0.0003 & 0.0005 & -0.9 & 0.00006 & 0.00006 & 0.0 \\
\hline \multicolumn{7}{|l|}{ Employer size } \\
\hline$<5$ & 0.1625 & 0.0449 & 39.3 & 0.1014 & 0.0981 & 1.1 \\
\hline $5-9$ & 0.1154 & 0.0461 & 25.6 & 0.1009 & 0.0977 & 1.1 \\
\hline $10-19$ & 0.1196 & 0.0628 & 19.8 & 0.1136 & 0.1118 & 0.6 \\
\hline $20-49$ & 0.1551 & 0.1122 & 12.6 & 0.1653 & 0.1652 & 0.0 \\
\hline $50-99$ & 0.0821 & 0.0753 & 2.5 & 0.0845 & 0.0866 & -0.8 \\
\hline $100-199$ & 0.0700 & 0.0774 & -2.8 & 0.0749 & 0.0787 & $\begin{array}{l}-0.0 \\
-1.5\end{array}$ \\
\hline $200-499$ & 0.0819 & 0.1053 & -8.0 & 0.0934 & 0.0983 & -1.7 \\
\hline $500-999$ & 0.0518 & 0.0743 & -9.3 & 0.0617 & 0.0611 & 0.2 \\
\hline$\geqslant 1000$ & 0.1612 & 0.4012 & -55.4 & 0.2041 & 0.2020 & 0.5 \\
\hline Nr. of employers & 2.0411 & 1.6561 & 35.2 & 1.7019 & 1.7146 & -1.3 \\
\hline Nr. of quarters unemployed & 2.3338 & 0.9669 & 40.5 & 1.2817 & 1.3079 & -0.9 \\
\hline Employer tenure & 10.25 & 11.964 & -29.3 & 12.263 & 12.149 & 2.0 \\
\hline Industry tenure & 12.224 & 14.544 & -46.4 & 14.032 & 13.938 & 2.0 \\
\hline Daily wage & 124.88 & 118.51 & 7.3 & 109.19 & 109.19 & 0.0 \\
\hline Wage growth & 0.0699 & 0.0686 & 0.2 & 0.0632 & 0.0489 & 2.3 \\
\hline Partner works & 0.2973 & 0.2371 & 13.6 & 0.2835 & 0.2860 & -0.6 \\
\hline Partner works\#partner daily wage & 31.572 & 24.17 & 9.5 & 27.355 & 26.727 & 1.3 \\
\hline Partner entrepreneurship experience & 0.0526 & 0.0306 & 11.0 & 0.0296 & 0.0314 & -1.0 \\
\hline Observations & 87614 & 835969 & & 32473 & 32473 & \\
\hline
\end{tabular}

Comparison of means between entrepreneurs and matched employees in the full and matched samples in the first quarter of 2004 . The standardized \% bias is the \% difference of the sample means between the entrepreneurs and matched employees as a percentage of the square root of the average of the sample variances of both groups 
Table A2: Balance of a k2k Coarsened exact matched sample

\begin{tabular}{|c|c|c|c|}
\hline & Entrepreneurs & Wage employees & Standardized \%bias \\
\hline \multicolumn{4}{|l|}{ Age } \\
\hline $22-24$ & 0.108 & 0.108 & 0.0 \\
\hline $25-29$ & 0.319 & 0.319 & 0.0 \\
\hline $30-34$ & 0.253 & 0.253 & 0.0 \\
\hline $35-39$ & 0.170 & 0.170 & 0.0 \\
\hline $40-44$ & 0.098 & 0.098 & 0.0 \\
\hline $45-49$ & 0.052 & 0.052 & 0.0 \\
\hline Female & 0.261 & 0.261 & 0.0 \\
\hline Flanders & 0.640 & 0.640 & 0.0 \\
\hline Wallonia & 0.260 & 0.260 & 0.0 \\
\hline Brussels & 0.100 & 0.100 & 0.0 \\
\hline \multicolumn{4}{|l|}{ Household position } \\
\hline Living with parents & 0.151 & 0.151 & 0.0 \\
\hline Single & 0.160 & 0.160 & 0.0 \\
\hline Cohabiting - 0 children & 0.219 & 0.219 & 0.0 \\
\hline Cohabiting -1 child & 0.172 & 0.172 & 0.0 \\
\hline Cohabiting -2 children & 0.167 & 0.167 & 0.0 \\
\hline Cohabiting $-3>$ children & 0.071 & 0.071 & 0.0 \\
\hline Head 1 parent family - 1 child & 0.013 & 0.013 & 0.0 \\
\hline Head 1 parent family $-2>$ children & 0.012 & 0.012 & 0.0 \\
\hline Other & 0.035 & 0.035 & 0.0 \\
\hline \multicolumn{4}{|l|}{ Occupation } \\
\hline Blue-collar & 0.330 & 0.330 & 0.0 \\
\hline White-collar/Govt. official & 0.668 & 0.668 & 0.0 \\
\hline Public sector & 0.053 & 0.053 & 0.2 \\
\hline \multicolumn{4}{|l|}{ Employer Industry } \\
\hline Manufacturing & 0.155 & 0.155 & 0.0 \\
\hline Electricity, gas, water & 0.002 & 0.002 & 0.0 \\
\hline Construction & 0.138 & 0.138 & 0.0 \\
\hline Wholesale and retail trade & 0.223 & 0.223 & 0.0 \\
\hline Hotels and restaurants & 0.034 & 0.034 & 0.0 \\
\hline Transport, storage, communication & 0.075 & 0.075 & 0.0 \\
\hline Financial institutions & 0.042 & 0.042 & 0.0 \\
\hline Real estate and professional services & 0.205 & 0.205 & 0.0 \\
\hline Public administration, defence & 0.013 & 0.013 & 0.0 \\
\hline Education & 0.014 & 0.014 & 0.0 \\
\hline Healthcare and support services & 0.052 & 0.052 & 0.0 \\
\hline Social and cultural services & 0.048 & 0.048 & 0.0 \\
\hline Households as employers & 0.000 & 0.000 & 0.0 \\
\hline \multicolumn{4}{|l|}{ Employer size } \\
\hline$<5$ & 0.165 & 0.165 & 0.0 \\
\hline $5-9$ & 0.119 & 0.119 & 0.0 \\
\hline $10-19$ & 0.132 & 0.132 & 0.0 \\
\hline $20-49$ & 0.163 & 0.163 & 0.0 \\
\hline $50-99$ & 0.091 & 0.091 & 0.0 \\
\hline $100-199$ & 0.079 & 0.079 & 0.0 \\
\hline $200-499$ & 0.082 & 0.082 & 0.0 \\
\hline $500-999$ & 0.054 & 0.054 & 0.0 \\
\hline$\geq 1000$ & 0.113 & 0.113 & 0.0 \\
\hline$\overline{\text { Nr}}$. of employers & 2.203 & 2.206 & -0.2 \\
\hline Nr. of quarters unemployed & 2.422 & 2.291 & 3.4 \\
\hline Employer tenure & 9.084 & 9.047 & 0.6 \\
\hline Industry tenure & 11.360 & 11.373 & -0.2 \\
\hline Daily wage & 12.126 & 11.944 & 3.0 \\
\hline Wage growth & 0.059 & 0.054 & 0.8 \\
\hline Partner works & 0.285 & 0.284 & 0.1 \\
\hline Partner works\#partner daily wage & 2.987 & 2.822 & 3.2 \\
\hline Partner entrepreneurship experience & 0.050 & 0.051 & -0.7 \\
\hline Observations & 9835 & 9835 & \\
\hline
\end{tabular}

Comparison of means between entrepreneurs and matched employees in the first quarter of 2004 for a k2k Coarsened Exact Matched sample. Mean values for most of the variables of this sample are highly similar to those obtained after the propensity score matching. Because we imposed to use the existing categories of the categorical variables as bins to create the strata, there is perfect balance on all these variables, but at the cost 5 f much more observations being discarded to obtain balance and an equal number of observations in both the entrepreneur and control groups than in the propensity score matching. To increase this number would require further coarsening of both the continuous and categorical variables, leading to non-zero imbalance on most of the (categorical) variables. 
Table A3: Balance of retained and dropped samples

\begin{tabular}{|c|c|c|c|}
\hline & Retained & Dropped & Std. \% bias \\
\hline \multicolumn{4}{|l|}{ Age } \\
\hline $22-24$ & 0.0841 & 0.0865 & -0.9 \\
\hline $25-29$ & 0.3092 & 0.3219 & -2.7 \\
\hline $30-34$ & 0.2767 & 0.2659 & 2.4 \\
\hline $35-39$ & 0.1923 & 0.1717 & 5.3 \\
\hline $40-44$ & 0.1078 & 0.1031 & 1.5 \\
\hline $45-49$ & 0.0300 & 0.0511 & -10.7 \\
\hline Female & 0.1056 & 0.2166 & -30.5 \\
\hline \multicolumn{4}{|l|}{ Region } \\
\hline Flanders & 0.7665 & 0.7879 & -5.2 \\
\hline Wallonia & 0.2156 & 0.1924 & 5.8 \\
\hline Brussels & 0.0179 & 0.0197 & -1.3 \\
\hline \multicolumn{4}{|l|}{ Household position } \\
\hline Living with parents & 0.1926 & 0.1919 & 0.2 \\
\hline Single & 0.1171 & 0.1211 & -1.2 \\
\hline Cohabiting - no children & 0.1941 & .2047 & -2.7 \\
\hline Cohabiting -1 child & 0.1742 & 0.1800 & -1.5 \\
\hline Cohabiting - 2 children & 0.2067 & 0.1980 & 2.2 \\
\hline Cohabiting - 3 or more children & 0.0691 & 0.0633 & 2.3 \\
\hline Head 1 parent family -1 child & 0.0082 & 0.0087 & -0.5 \\
\hline Head 1 parent family - 2 or more children & 0.0068 & 0.0068 & 0.0 \\
\hline Other & 0.0316 & 0.0253 & 3.5 \\
\hline \multicolumn{4}{|l|}{ Occupation } \\
\hline Blue-collar & 0.5207 & 0.4690 & 10.4 \\
\hline White-collar & 0.4355 & 0.4840 & -9.7 \\
\hline Govt. official & 0.0439 & 0.0471 & -1.5 \\
\hline \multicolumn{4}{|l|}{ Employer sector } \\
\hline Public & 0.0764 & .0893 & -4.7 \\
\hline \multicolumn{4}{|l|}{ Employer Industry } \\
\hline Manufacturing & 0.2423 & 0.2540 & -2.7 \\
\hline Electricity, gas, water & 0.0000 & .0005 & -3.1 \\
\hline Construction & 0.2317 & 0.1869 & 11.0 \\
\hline Wholesale and retail trade & 0.2153 & 0.2061 & 2.2 \\
\hline Hotels and restaurants & 0.0102 & 0.0099 & 0.3 \\
\hline Transport, storage, communication & 0.0826 & 0.0621 & 7.9 \\
\hline Financial institutions & 0.0296 & 0.0333 & -2.1 \\
\hline Real estate and professional services & 0.1203 & 0.1323 & -3.6 \\
\hline Public administration, defence & 0.0311 & 0.0279 & 1.9 \\
\hline Education & 0.0190 & 0.0266 & -5.1 \\
\hline Healthcare and support services & 0.0113 & 0.0487 & -22.0 \\
\hline Social and cultural services & 0.0066 & 0.0117 & -5.4 \\
\hline Households as employers & 0.0000 & 0.0003 & -0.8 \\
\hline \multicolumn{4}{|l|}{ Employer size } \\
\hline$<5$ & 0.0917 & 0.1005 & -3.0 \\
\hline $5-9$ & 0.0996 & 0.0993 & 0.1 \\
\hline $10-19$ & 0.1083 & 0.1131 & -1.5 \\
\hline $20-49$ & 0.1888 & 0.1631 & 6.7 \\
\hline $50-99$ & 0.0928 & 0.0849 & 2.8 \\
\hline $100-199$ & 0.0802 & 0.0765 & 1.4 \\
\hline $200-499$ & 0.1014 & 0.0954 & 2.0 \\
\hline $500-999$ & 0.0556 & 0.0610 & -2.7 \\
\hline$\geqslant 1000$ & 0.1815 & 0.2051 & -6.0 \\
\hline Nr. of jobs & 1.8957 & 1.7339 & 11.8 \\
\hline Employer tenure (quarters) & 11.712 & 12.257 & -9.7 \\
\hline Daily wage & 108.98 & 109.25 & -0.8 \\
\hline Observations & 5,470 & 59,476 & \\
\hline
\end{tabular}

Comparison of means of selected variables between the retained and dropped sub-samples in the 1st quarter of 2004. 
Table A4: Comparisons at pre-entry time of entrepreneurs with and without a mover matched pair

\begin{tabular}{|c|c|c|c|c|c|c|c|c|}
\hline \multirow{3}{*}{$\begin{array}{l}\text { Matched employees changes jobs } \\
\text { Age }\end{array}$} & \multicolumn{4}{|c|}{ Mover at entry in entrepreneurship } & \multicolumn{4}{|c|}{ Mover at re-entry in wage work } \\
\hline & \multicolumn{2}{|c|}{ Mean } & \multicolumn{2}{|c|}{ t-test } & \multicolumn{2}{|c|}{ Mean } & \multicolumn{2}{|c|}{ t-test } \\
\hline & Yes & No & $\mathrm{t}$ & $\mathrm{p}>\mathrm{t}$ & Yes & No & $\mathrm{t}$ & $\mathrm{p}>\mathrm{t}$ \\
\hline $22-24$ & 0.02664 & 0.0178 & 1.28 & 0.199 & 0.0241 & 0.01811 & 0.93 & 0.353 \\
\hline $25-29$ & 0.25 & 0.18781 & 3.12 & 0.002 & 0.19449 & 0.20009 & -0.30 & 0.764 \\
\hline $30-34$ & 0.36066 & 0.27948 & 3.57 & 0.000 & 0.30293 & 0.29155 & 0.53 & 0.593 \\
\hline $35-39$ & 0.18648 & 0.24344 & -2.70 & 0.007 & 0.22719 & 0.23491 & -0.39 & 0.696 \\
\hline $40-44$ & 0.1127 & 0.17134 & -3.20 & 0.001 & 0.16179 & 0.16063 & 0.07 & 0.946 \\
\hline $50-54$ & 0.01025 & 0.0178 & -1.19 & 0.234 & 0.01549 & 0.01671 & -0.21 & 0.837 \\
\hline $55-59$ & 0.00205 & 0.00045 & 1.19 & 0.235 & 0.00172 & 0.00046 & 0.99 & 0.320 \\
\hline Female & 0.10246 & 0.10636 & -0.25 & 0.799 & 0.08434 & 0.11142 & -1.89 & 0.060 \\
\hline \multicolumn{9}{|l|}{ Region } \\
\hline Flanders & 0.84016 & 0.74944 & 4.30 & 0.000 & 0.76592 & 0.76555 & 0.02 & 0.985 \\
\hline Wallonia & 0.14959 & 0.23186 & -4.01 & 0.000 & 0.21687 & 0.21727 & -0.02 & 0.983 \\
\hline Brussels & 0.01025 & 0.01869 & -1.30 & 0.193 & 0.01721 & 0.01718 & 0.01 & 0.995 \\
\hline Living with parents & 0.10861 & 0.10903 & -0.03 & 0.978 & 0.11188 & 0.10817 & 0.25 & 0.799 \\
\hline Single & 0.13115 & 0.12328 & 0.48 & 0.633 & 0.12909 & 0.12349 & 0.36 & 0.717 \\
\hline Cohabiting - 0 children & 0.18648 & 0.17713 & 0.49 & 0.625 & 0.16179 & 0.18338 & -1.21 & 0.228 \\
\hline Cohabiting - 1 child & 0.21107 & 0.1927 & 0.93 & 0.354 & 0.2117 & 0.19174 & 1.08 & 0.282 \\
\hline Cohabiting - 2 children & 0.25 & 0.25501 & -0.23 & 0.818 & 0.26334 & 0.25162 & 0.58 & 0.565 \\
\hline Cohabiting - 3 or more children & 0.07172 & 0.09613 & -1.69 & 0.091 & 0.08606 & 0.09331 & -0.54 & 0.591 \\
\hline Head 1 parent family - 1 child & 0.0082 & 0.00801 & 0.04 & 0.967 & 0.00516 & 0.00882 & -0.88 & 0.381 \\
\hline Head 1 parent family - 2 or more children & 0.01025 & 0.00757 & 0.60 & 0.548 & 0.00861 & 0.01161 & -0.62 & 0.538 \\
\hline Other & 0.01844 & 0.01869 & -0.04 & 0.971 & 0.01549 & 0.0195 & -0.63 & 0.526 \\
\hline \multicolumn{9}{|l|}{ Occupation } \\
\hline Blue-collar & 0.54303 & 0.49666 & 1.86 & 0.063 & 0.52496 & 0.49954 & 1.09 & 0.277 \\
\hline White collar & 0.43443 & 0.45972 & -1.02 & 0.309 & 0.46127 & 0.45357 & 0.33 & 0.741 \\
\hline Govt. Official & 0.02254 & 0.04361 & -2.16 & 0.031 & 0.01377 & 0.04689 & -3.63 & 0.000 \\
\hline \multicolumn{9}{|l|}{ Job regime } \\
\hline Full-time & 1 & 1 & . & . & 1 & 1 & . & . \\
\hline Public sector & 0.04918 & 0.07788 & -2.21 & 0.027 & 0.04131 & 0.08124 & -3.29 & 0.001 \\
\hline Electricity, gas, water & 0.00205 & 0.00089 & 0.70 & 0.483 & 0 & 0.00139 & -0.90 & 0.368 \\
\hline Construction & 0.28893 & 0.23097 & 2.71 & 0.007 & 0.25473 & 0.2377 & 0.85 & 0.395 \\
\hline Wholesale and retail trade & 0.20697 & 0.21451 & -0.37 & 0.712 & 0.22031 & 0.21123 & 0.47 & 0.636 \\
\hline Hotels and restaurants & 0.01025 & 0.01202 & -0.33 & 0.742 & 0.01893 & 0.00975 & 1.83 & 0.068 \\
\hline Transport, storage, communication & 0.09221 & 0.08767 & 0.32 & 0.749 & 0.09639 & 0.08635 & 0.76 & 0.450 \\
\hline Financial institutions & 0.03279 & 0.03204 & 0.08 & 0.933 & 0.0327 & 0.03203 & 0.08 & 0.935 \\
\hline Real estate and professional services & 0.15574 & 0.12461 & 1.85 & 0.064 & 0.16351 & 0.12117 & 2.69 & 0.007 \\
\hline Public administration, defence & 0.03074 & 0.03204 & -0.15 & 0.882 & 0.01377 & 0.03668 & -2.80 & 0.005 \\
\hline Education & 0.0082 & 0.02136 & -1.93 & 0.054 & 0.01377 & 0.02043 & -1.04 & 0.297 \\
\hline Healthcare and support services & 0.00615 & 0.01424 & -1.44 & 0.149 & 0.00688 & 0.01439 & -1.43 & 0.153 \\
\hline Social and cultural services & 0.00205 & 0.01335 & -2.14 & 0.033 & 0.00861 & 0.01207 & -0.70 & 0.484 \\
\hline Households as employers & 0 & 0.00045 & -0.47 & 0.641 & 0 & 0.00046 & -0.52 & 0.604 \\
\hline \multicolumn{9}{|l|}{ Employer Size } \\
\hline$<5$ & 0.18033 & 0.12639 & 3.16 & 0.002 & 0.15491 & 0.13092 & 1.50 & 0.135 \\
\hline $5-9$ & 0.13934 & 0.11259 & 1.66 & 0.096 & 0.13425 & 0.11281 & 1.42 & 0.154 \\
\hline $10-19$ & 0.13115 & 0.1166 & 0.90 & 0.369 & 0.13597 & 0.11467 & 1.41 & 0.160 \\
\hline $20-49$ & 0.17418 & 0.18069 & -0.34 & 0.734 & 0.18761 & 0.17734 & 0.57 & 0.567 \\
\hline $50-99$ & 0.09426 & 0.081 & 0.96 & 0.337 & 0.08262 & 0.08357 & -0.07 & 0.941 \\
\hline $100-199$ & 0.04918 & 0.06631 & -1.41 & 0.159 & 0.06196 & 0.0636 & -0.14 & 0.885 \\
\hline $200-499$ & 0.07992 & 0.085 & -0.37 & 0.714 & 0.09466 & 0.08124 & 1.03 & 0.301 \\
\hline $500-999$ & 0.03893 & 0.05251 & -1.25 & 0.213 & 0.03787 & 0.05339 & -1.52 & 0.128 \\
\hline$\geq 1000$ & 0.1127 & 0.17891 & -3.56 & 0.000 & 0.11015 & 0.18245 & -4.16 & 0.000 \\
\hline $\mathrm{Nr}$. of employers & 2.9857 & 2.7512 & 2.07 & 0.038 & 3.0052 & 2.7358 & 2.55 & 0.011 \\
\hline Employer tenure & 15.209 & 16.509 & -2.21 & 0.027 & 16.413 & 16.24 & 0.31 & 0.755 \\
\hline Daily wage & 122.62 & 128.72 & -2.33 & 0.020 & 133.7 & 125.99 & 3.15 & 0.002 \\
\hline Observations & 488 & 2,274 & & & 581 & 2,154 & & \\
\hline
\end{tabular}




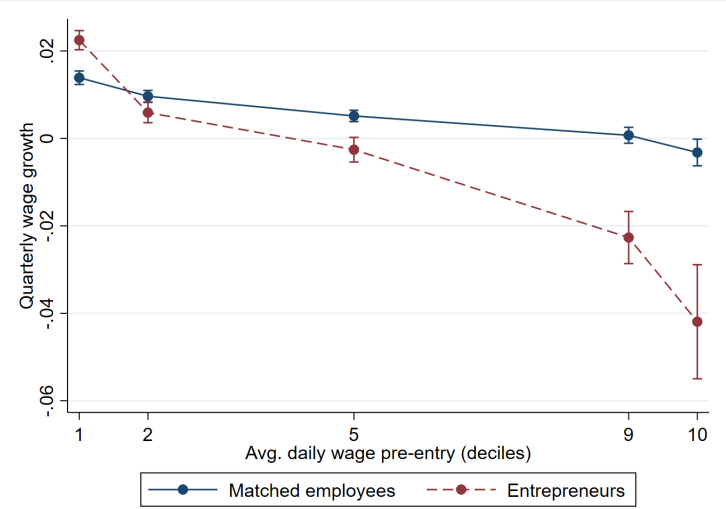

Figure A1: Full sample

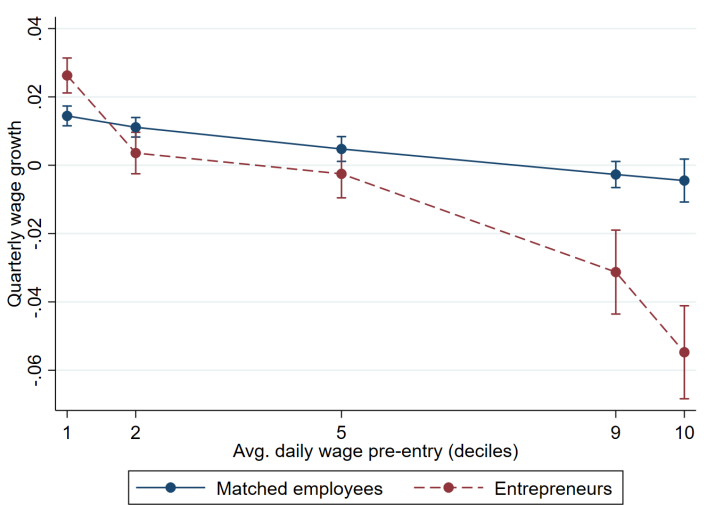

Figure A2: Part-time workers

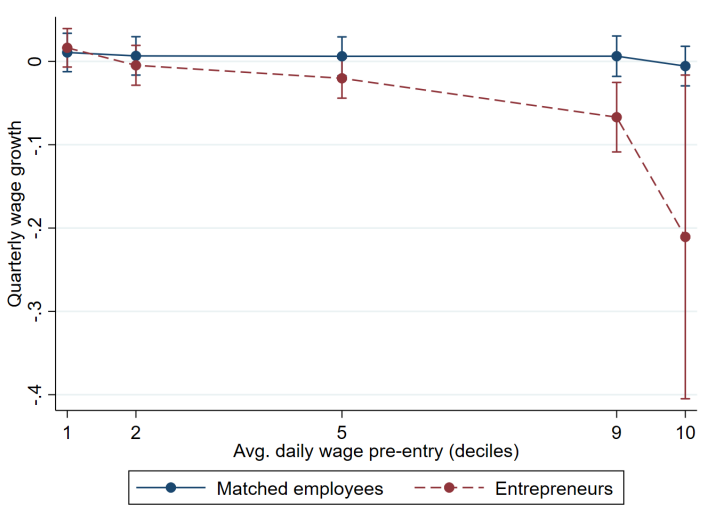

Figure A3: Temporary workers

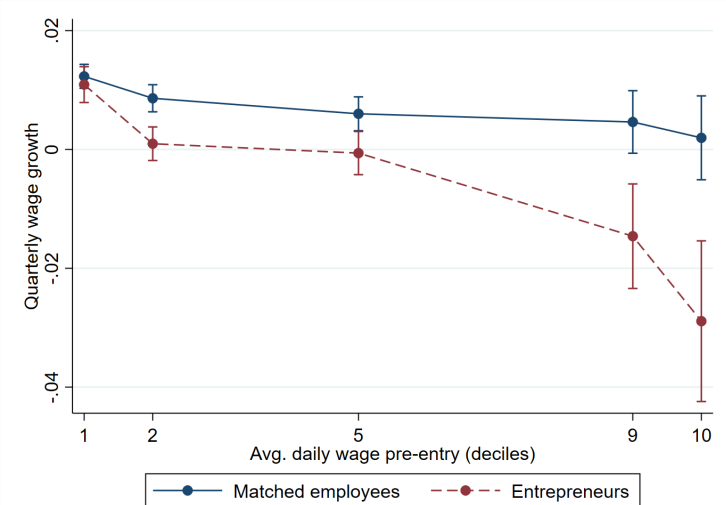

Figure A4: Necessity entry into entrepreneurship

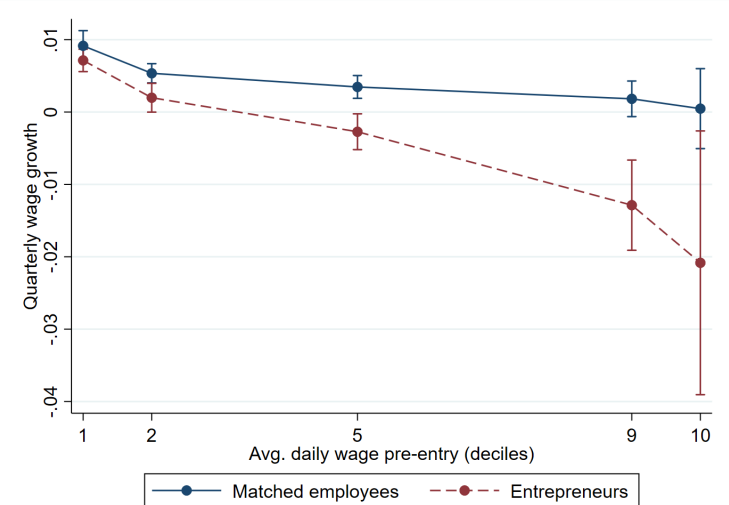

Figure A5: Necessity exit out of entrepreneurship 


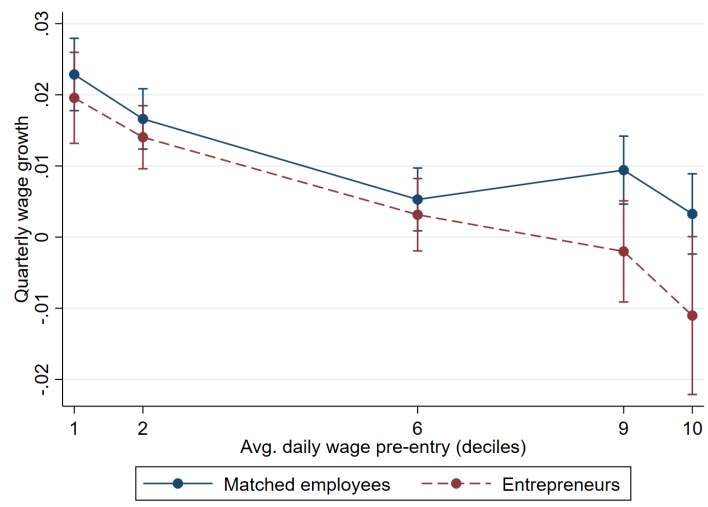

Figure A6: Predictive margins of entrepreneurs and matched employees who change jobs at the time entrepreneurs enter into entrepreneurship

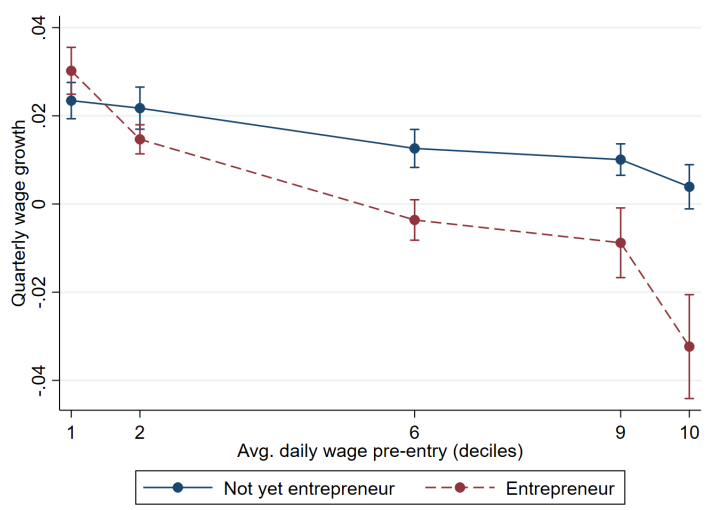

Figure A7: Predictive margins of entrepreneurs who return to wage work before or at the 1st quarter of 2011 and of "Not yet" entrepreneurs who did not enter entrepreneurship until the 2nd quarter of 2011 